\title{
Becoming White: How Military Service Turned Immigrants into Americans ${ }^{*}$
}

\author{
Soumyajit Mazumder ${ }^{\dagger}$ \\ Harvard University \\ smazumder@g.harvard.edu
}

Word Count: 9962

What factors help to explain the cultural integration of immigrants? I argue that individual participation in military service creates a number of conditions that drive individuals to integrate into a broader national culture. To test the hypothesis, I focus on the case of World War I in the United States-a period that closely followed a massive wave of immigration into the United States. Using data on the entire population of immigrants in the U.S., I show that men of foreign, European nativity were more likely to integrate into American society after serving in the U.S. military. Heterogeneous effects suggest some scope for the importance of wartime social networks. This article contributes to our understanding of the ways in which states make identity and the prospects for immigrant integration in an age without mass warfare.

\footnotetext{
${ }^{*}$ I am deeply indebted to James Feigenbaum for providing me access to the restricted files for the U.S. Census. Moreover, I am also grateful for the efforts of Ancestry.com and the Minnesota Population Center in transcribing, cleaning, and providing public access to individual-level census data. I would like to thank Angie Bautista-Chavez, Matt Blackwell, Dan Carpenter, Dara Cohen, Ryan Enos, Jeff Frieden, Vicky Fouka, Siddharth George, Jennifer Hochschild, Dan Magleby, Nathan Nunn, Marco Tabellini, Didac Queralt, Hye-Young You, and Yuri Zhukov for helpful conversations and feedback during various stages of this project. Additionally, I would also like to thank seminar audiences at Boston University and Harvard University as well as participants of the Harvard-MIT-Tufts-Yale Political Violence Workshop, the 2018 Politics and History Conference, EITM 2018, and the Northeast Workshop in Empirical Political Science Fall 2018 meeting for helpful comments and suggestions. All errors are, of course, my own.

${ }^{\dagger}$ Ph.D. Candidate, Department of Government, Harvard University, web: http:// smazumder.me
} 


\section{INTRODUCTION}

National culture and citizenship are foundational concepts to the construction of nation-states. As history tells us, though, constructing a truly national citizenry involves a long and often arduous process. In cases such as France, Weber (1976) shows how processes of modernization helped to create a French, national citizenry in the countryside. Other cases such as Ireland show how competing conceptions of identity can come into bloody conflict with hegemonic, national cultures. In essence, the relationship between national culture-shared values and beliefs-and citizenship-the encoding of national identity into law-depends on having a citizenry that believes itself to be part of an "imagined community" (Anderson 1983).

But in a world where individuals have the ability to move from one nation to another, newly arrived groups at the social periphery generally do not instantly become a part of this dominant culture. Instead, these groups often lie at the periphery of the dominant group (the social core). This paper will focus on one specific instance of social core-periphery relations: the relationship between immigrants (the periphery group) and native-born individuals (the core group) in the early 20th century United States. Whether periphery members integrate into the dominant national culture depends on whether these new groups wish to join the dominant, national group and on the social core's willingness to accept these new groups into their own. The core puzzle, then, can be stated as follows: how do groups on the social periphery integrate into the social core of a nation? Within the context of this paper, how did immigrants, who were considered as outsiders in the early 20th century, become Americans?

Building on a rich literature within history and the social sciences, I argue that individual participation in military service can be a powerful force of integration of periphery group members into the social core. From the literature, I derive two core (but non-exhaustive) mechanisms through which military service can shape immigrant integration. First, military service could lead to direct inculcation of immigrants by impressing upon them their new host country's values. Second, military service could also spur integration by reducing feelings of ani- 
mosity between immigrants and native-born individuals through intense intergroup contact and socialization. ${ }^{1}$ Together, these mechanisms suggest that military service should help to drive immigrant integration.

To test the argument, I focus on the case of the United States' involvement in World War I (1917-1918)-a period that rapidly followed the end of the Age of Mass Migration. This period saw a massive influx of European immigration largely of Italians, Germans, and Eastern Europeans into the United States (Abramitzky, Boustan, and Eriksson 2012, 2014). Though we now consider these groups to be "white Americans" today, the Irish, Italians, Jews, and Germans were only one step up above African Americans in the American racial hierarchy at the time. Given that these ethnic groups were on the cultural periphery, studying them in the context of the First Great War provides as close to an ideal case as possible in terms of their integration patterns with respect to war service. This context is also useful from an inferential perspective. The exogenous timing with respect to birth cohorts facilitates using an instrumental variables strategy for causal identification. Together, these features make this case useful both substantively and empirically.

Using both an ordinary least squares (OLS) and instrumental variables (IV) strategy paired with newly digitized, individual-level data on all immigrants living in the United States in 1930, I find that first-generation, male immigrants who served in the military during World War I (WWI) were more likely to marry native-born women and become naturalized citizens-two costly, behavioral proxies for integration. OLS results are robust to the inclusion of birth year fixed effects, year of immigration fixed effects, ethnic group fixed effects, and county fixed ef-

\footnotetext{
${ }^{1}$ Throughout the rest of this paper, I use native-born to refer to white citizens who are be-
} yond second generation immigration status. The use of this term has inherent limitations to it with respect to the experiences of the pre-existing indigenous population as well as the black population at the time. In this respect, the type of integration (described in further detail below) is "racialized" in this sense. 
fects in addition to alternative matching estimators. Sensitivity analysis of the key identifying assumption behind the OLS results suggests that the OLS estimates are insensitive to potential unobserved confounders. I also pursue an IV empirical strategy that leverages the exogenous timing of the war in producing differential enlistment variation across cohorts. Using this variation as an instrumental variable, I find that the results remain substantively and statistically significant. Finally to assuage concerns over the validity of the exclusion restriction for IV designs, I apply a bias-correction procedure using placebo samples and show the conclusions remain unchanged. Together, the data and results show that military service seems to produce meaningful levels of immigrant integration into American national culture.

To further validate the argument, I investigate the socialization mechanism. While data availability and the lack of researcher control makes it challenging to make precise conclusions as to the role of each mechanism proposed in this article, I am able to generate estimates of the county-level proportion of native-born WWI veterans to proxy for the existence of wartime social networks (one dimension of socialization). Heterogeneity along this dimension demonstrates some role for the ability of wartime social networks to foster the integration of immigrant veterans. Importantly, I find that there is still a substantial effect even for immigrants living in counties with very low proportions of native-born veterans suggesting that the other inculcation and acceptance mechanisms might also be operating. Together, these results provide further support for the argument advanced in this article.

Though a large literature tends to treat identities as largely static, this paper builds on the field of "whiteness" studies to show the intimate role of the state in shaping the transformation of immigrants-who were considered less than white in a cultural sense-into white Americans (Ignatiev 1995; Roediger 1999; King 2000; Fouka, Mazumder, and Tabellini 2019). Though much of this literature tends to focus on the way in which intergroup contact shapes immigrants' sense of white, American identity, I draw on the state-building and nationalism literatures to show how the state has a particularly important role in shaping the boundaries of white 
identity (Weber 1976; Gellner 1983; Hobsbawm 1990; King 2000; Wimmer 2017). In particular, I show that mass mobilization for warfare has played a fundamental role in helping individuals at the social periphery to assimilate into the social core. While the classic insight from works that highlight the relationship between warfare and the state is that mass mobilization for warfare can be conducive to state-building (Tilly 1990; Bensel 1990), progressive institutions (Scheve and Stasavage 2016), and democracy (Levi 1997; Ferejohn and Rosenbluth 2016), this paper shows that this phenomenon runs much deeper: mass mobilization for warfare can fundamentally reshape our social identities. In this respect, this paper builds on Sambanis, Skaperdas, and Wohlforth (2015) who argue that warfare can increase national identification among the general populace. This study, however, places the focus on the direct effect of the military itself rather than the overall context of war. These themes also connects to the broader way in which the military, though one of the most conservative institutions, can also provide opportunities for minority groups to achieve social and political equality (Klinkner and Smith 1999; Krebs 2006; Parker 2010; Samii 2013). Though this study is unable to empirically arbitrate between the various mechanisms that could explain the link between military service and immigrant integration, the results in this article provide a stepping stone for future research to explore the mechanisms and contexts that lead to the relationship demonstrated in this study.

This paper also contributes to our understanding of the politics of immigrant integration, a topic of contemporary importance given the rising tension around immigration in the Western world (Hopkins 2010). While Adida, Laitin, and Valfort (2016) show that immigrants can get trapped in a "discriminatory equilibrium", I argue that the state has a key role to play in breaking this equilibrium. In line with the idea that the state has an important role in helping immigrants to assimilate into their respective nations, Hainmueller, Hangartner, and Pietrantuono (2017) and Hainmueller, Hangartner, and Pietrantuono (2015) find that the process of acquiring citizenship can break down barriers to, at least, the political incorporation of immigrants into a polity. These results show that military service might be one way in which 
to achieve integration beyond political incorporation, though this obviously raises a number of troubling normative issues. In related work, Mazumder (2019) shows how mass mobilization for war might be a unique force in creating national identity by showing that schooling, another nation-building institution hypothesized by classic works such as Hobsbawm (1990), seems to have a precise null effect on the formation of national identity among both immigrants and native-born citizens both historically and today. Moreover, Fouka (2019a) shows how language policies aimed at homogenizing and assimilating immigrants can actually backfire. In short, the state certainly has a role to play in integration immigrants into a nation, but the context in which this might happen at a large-scale suggests an irony in the process of immigrant integration: cultural incorporation of immigrants may come at the highest price.

\section{IMMIGRANT INTEGRATION AND THE STATE}

The primary outcome of interest in this article is the degree of immigrant integration. In this article, I focus on two key behavioral indicators of how integrated immigrants are into their new host societies: citizenship and intermarriage with native-born individuals. These indicators capture how well incorporated an immigrant is into the new national community both politically and socially (Harder et al. 2018). Moreover, they reflect the interaction between native-born individuals and immigrants in a way that moves beyond "cheap talk." Thus, the remainder of this article focuses on these variables as indicators of "successful" integration. ${ }^{2}$

Within the context of American history, integration into national culture has been explicitly and implicitly tied up with race, ethnicity, and, specifically, "whiteness" (Gordon 1964; Ignatiev 1995; Smith 1999; King 2000). As the sociologist Milton Gordon points out, integration into

${ }^{2}$ Immigrants can still be "successful" without shedding their previous identities (Harder et al. 2018). This process of integration is perhaps much more relevant for modern contexts in which the rhetoric and concept of assimilation is hotly contested. 
American culture has primarily taken the form of "Anglo-conformity" in which new groups assimilate into white, Anglo-Saxon culture rather than other forms of integration such as the "melting pot" whereby native-born individuals also take components of the identity of new groups in creating a revised national identity (Gordon 1964).

What these perspectives tend to overlook, however, is the important role of the state as an independent force in shaping both the desire for ethnic groups to integrate into the social core and the willingness of those in the social core to accept groups from the outside. Particularly, the state plays a major role in shaping the boundaries of identity. For example, scholars show that the act of counting and classifying ethnic groups through censuses play a major role in shaping how individuals think of themselves and how they might antagonize out-groups (Hochschild and Powell 2008; Lieberman and Singh 2017). Furthermore, states can also enforce racial hierarchies through coercion and social policy (Marx 1997; Katznelson 2014). The upshot from this literature is that we might suspect that the state could play a crucial role in the process of not only enforcing racial hierarchies, but facilitating certain groups to advance up it.

Despite highlighting the important role of the state in shaping identity formation, much of these studies tend to miss the ways in which even more fundamental features of the modern state such as war-making can also transform identities of its citizens (Tilly 1990). It is also important to note that the process of integration into the social core is not necessarily normatively desirable. The transformation of ethnic identity into a broader national identity synonymous with white, Anglo-Saxon Americans is about dealing with diversity by removing it (King 2000). In the following section, I lay out a theory of the way in which participation in mass warfare can lead individuals at the social periphery to assimilate into the social core of a polity. 


\section{HOW MILITARY SERVICE LEADS TO IMMIGRANT INTEGRATION}

In this section, I draw on a diverse set of literatures to develop a framework for understanding how participation in mass warfare can lead immigrants to integrate into American culture. To briefly summarize the theory, I argue that individuals from the social periphery-in this paper, I consider the case of immigrants in the United States during the Age of Mass Migrationwho serve in the military will be more likely to integrate into the social core of a nation. This can happen through a variety of mechanisms including direct inculcation and socialization. This theory suggest that the process of mass mobilization for warfare and particularly military service, though incredibly deleterious with respect to human life, might lead to the cultural incorporation of marginalized groups within a polity.

\section{Inculcation}

First, military service might change the preferences of immigrants through direct inculcation. While individuals may learn their sense of national identity formally during schooling (Hobsbawm 1990) or casually through their interaction with the banalities of life in a nation-state (Anderson 1983), there are very few institutions like the military where individuals have the importance of national identity impressed upon them. These individuals are constantly exposed to the symbols of the American state and its dominant culture such as the American flag (Kalmoe and Gross 2016; Levendusky, Forthcoming), common language (Laitin 1992), and the propaganda associated with a war effort (Yanagizawa-Drott 2014)-all of which have the ability to shift immigrants servicemen to want to become more integrated. Moreover, the process of military training involves stripping individuals of their pre-existing identities and building them up into soldiers willing to go to great lengths for their nation. For instance, Captain Ralston Flemming-the head intelligence officer at Camp Jackson in South Carolina, noted in a memo to President Woodrow Wilson that "It has been our purpose to endeavor to impress a spirit of enthusiastic militant Americanism upon these men and so far we have been very 
successful" (Flemming 1918). If this type of inculcation noted by Captain Flemming was instituted systematically, then we should expect military service to induce cultural integration by fundamentally shifting the preferences of immigrants to want to become Americans.

\section{Socialization}

Second, military service could also change immigrants' preferences for integration through socialization and intergroup contact. This mechanism lies at the heart of Weber (1976)'s account of the ways in which rural peasants in France gained their French national identity. Essentially, the military can reshape immigrants identity by exposing them to a wide variety of individuals especially natives who they would have otherwise not met or interacted with. Given that most socialization in the military would occur with whites, then we should expect immigrants to converge in their identities toward them following standard models of socialization in economics (Bisin and Verdier 2001). Moreover, the military is a ripe setting for intergroup contact to make immigrants feel closer to natives since the vast majority of individuals interact on an equal footing with each other and are required to cooperate with each other given battlefield objectives (Allport 1954; Wilcox 2011; Samii 2013). Recounting the experience of the 306th Infantry, the divisional historian noted that "All civilian associations were to be severed and a new comradeship, based on the men's experiences in the Regiment in peace and war, fostered, so that there might be borne into civilian life after the war a greater understanding of democracy" (Sterba 2003). Moreover, work in civil conflicts highlights the role of social networks acquired during war time (Weinstein 2006; Costa and Kahn 2008; Wood 2008; Parkinson 2013). By incorporating immigrants who might be in the periphery of the social networks of native-born men, the experience of training and fighting together can help to solidify wartime bonds even after the end of the war thereby helping to incorporate immigrants after the war. In short, the U.S. military did seem to recognize the value of generating new connections between immigrants and native-born men so as to push immigrants to adopt their host country's values. 


\section{THE AGE OF MASS MIGRATION, WORLD WAR I, AND THE UNITED}

\section{STATES}

To test the argument, I focus on the case of the United States during World War I. While one could plausibly test this theory across a variety of different settings especially in Western Europe, I argue that this setting is useful for a number of reasons. First, the timing of World War I intersected a massive period of migration into the United States over the course of the late 19th into the early 20th century. This supply of immigrants creates variation in the ability of immigrants to assimilate into American society and variation across ethnic groups in the degree to which some groups might have already assimilated. Second, World War I was, in many respects, the first war in which there was mass mobilization of the populace especially with regard to military recruitment. Given the emphasis on the importance of mass mobilization for nation and state-building in the historical and comparative literatures, World War I presents a useful case since it is emblematic of these features. These factors, then, make the case of the United States' experience during World War I an ideal setting in which to test this theory.

One such factor that I explore in this paper is the way in which World War I created structural conditions both conducive to cultural incorporation of immigrants and harmful for certain groups such as Germans. As mentioned before, World War I was one of the first modern conflicts with respect to its sheer scale of mobilization. Starting in 1914 in continental Europe, the United States spent much of the war articulating a non-interventionist position. It was only until Germany began a policy of unrestricted submarine warfare against shipping lines between the United States and Great Britain, which essentially forced President Woodrow Wilson's hand into joining the war-the timing of which was exogenous to the domestic conditions in the United States. Soon after declaring war against Germany and the Central Powers, the United States instituted multiple waves of compulsory military service ultimately leading the United States to have over four million men serving in the war. Despite the rise in discrimi- 
nation against Germans during this time period, Fouka (2019b) shows that Germans actually increased their efforts at integration by giving their children more American sounding names and by filing more petitions for citizenship. Though this political context is important, I explore how the direct participation in the war effort shaped integration patterns and then explore how this context might have differentially affected a variety of different ethic groups.

\section{RESEARCH DESIGN AND RESULTS}

The theory suggests that immigrant men who serve in the military should become more assimilated into American society and culture. This requires evaluating the counter-factual claim of what would have happened to an individual had he not served in World War I. To assess this, I use two different strategies. First, I estimate a series OLS regressions that use rich information on background covariates to allow for the use of birth year, year of immigration, ethnic group, and geographic fixed effects. Second, I use an instrumental variables design inspired by Campante and Yanagizawa-Drott (2016) that leverages the interaction of an individual's birth cohort with respect to the timing of the war. For both strategies, I also show that they are robust to estimation strategies and deviations from the key identifying assumptions. With these identification strategies, I use individual-level data from the 1930 U.S. Census-the first census to record WWI veteran-status-to assess the degree to which military service among immigrants led to their integration into American society.

\section{Data and Estimation}

To test the relationship between war experience and cultural integration, I primarily rely on individual-level data from the 1930 decennial U.S. Census. While ideally one would use the

full service records for all males who either volunteered or were conscripted into the military during WW1, these records were unfortunately destroyed in a fire at the U.S. National Archives 
in 1973. As a next best data source, I utilize the 1930 U.S. Census, which is the first census to collect data on an individual's service in WWI. ${ }^{3}$ These individual-level censuses are a rich and largely untapped source of data in political science. The decennial census contains a wealth of information including an individual's nativity, education, occupation, and residence among a whole host of other variables. As one might notice, veteran status itself is measured posttreatment, which could induce bias into any statistical analyses. Importantly, the casualty rate for Americans was fortunately quite low $(\approx 100,000$ or around $0.2 \%$ of all infantry). Since these rates were so low, it is unlikely that non-random variation in casualty rates could induce any substantial bias into these results. In sum, the granularity of this data and the large sample size allows me to study heterogeneous effects by ethnic groups and across outcomes while conserving sufficient power for the instrumental variables strategy.

War Service: The primary independent variable of interest is whether a male of foreign nativity served in the military during WWI. One point to note is that this measure only captures those individuals who survived the war. Because casualties are plausibly exogenous and since the overall casualty rate was actually quite low (around 4\%), this issue should not significantly threaten any inferences. Overall, the mobilization rate among immigrants was approximately $6 \%$. Figure 1 plots the distribution of the county-level mobilization rate by state. While there seems to be very little variation across states, there does seem to be substantial geographic variation across counties within states. To account for this, the main estimating equations will rely on county fixed effects so as to only compare individuals within a given county in a certain state.

Cultural Integration: The primary dependent variable of interest is the degree to which male, immigrants are able to culturally integrate into the social core-in this case, white, American society. This, of course, is quite a broad concept; moreover given the lack of fine-grained

${ }^{3}$ Unfortunately, data from the Census does not allow me to discern whether an individual was drafted or volunteered. 
Figure 1: World War I Mobilization by State among Immigrants

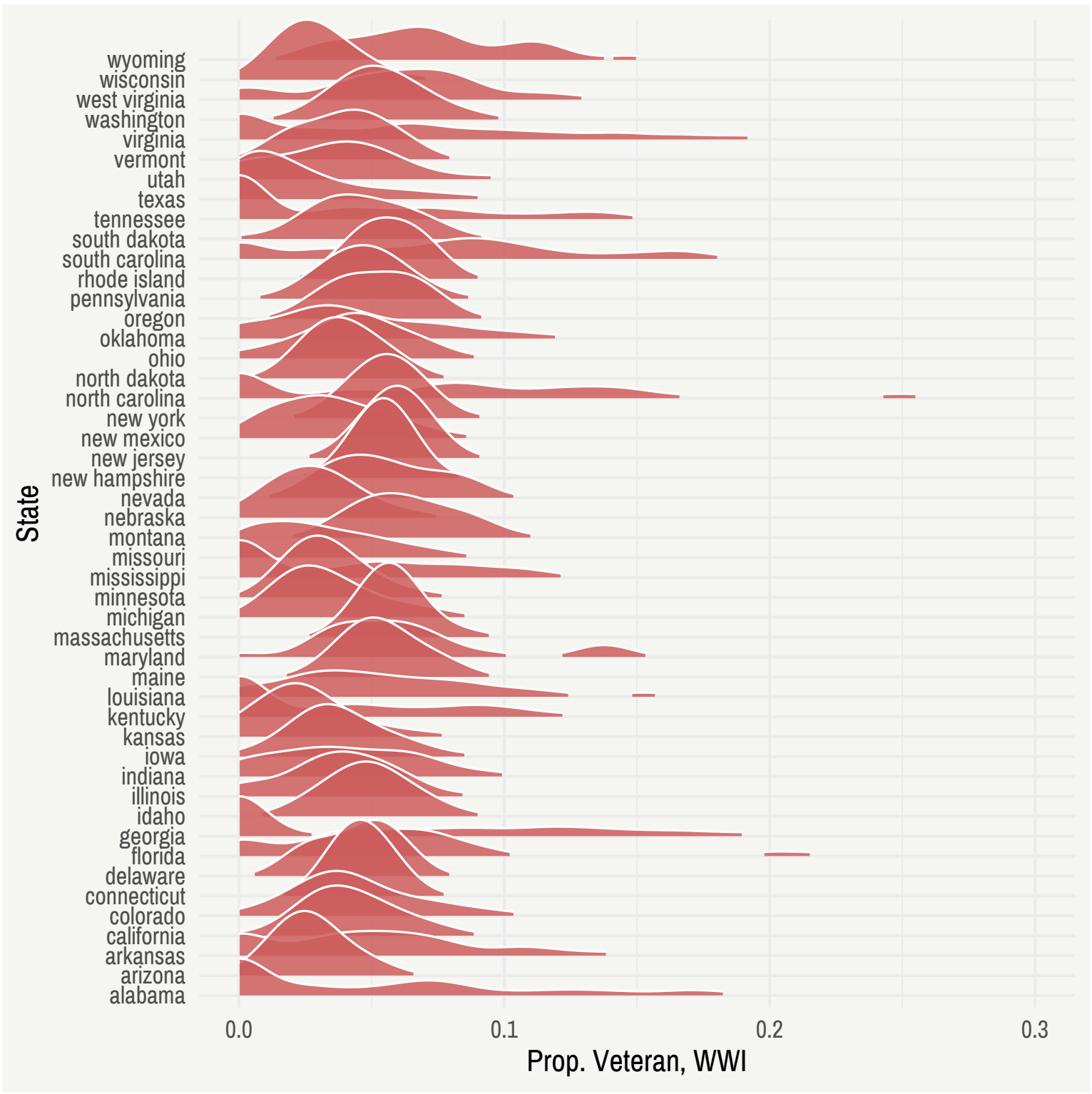

.Source: 1930 U.S. Census from IPUMS 
survey data during this time, it is impossible to quantitatively know how immigrants perceived their social identity. Instead, I rely on several key behavioral measures that I can compute during this time period: marriage to native-born vs. immigrants, naturalization, and naming conventions. The first two outcomes capture both the effort and acceptance of an immigrant into American society, while the latter allows me to isolate the individual role of immigrant effort. I explain the logic for each measure below.

Marriage: Marriage is both an expression of love and one's own social identity. A wealth of research across the social sciences shows how preferences over social groups shape marriage patterns across race, class, and partisanship (Alford et al. 2011; Huber and Malhotra 2016). If marriage is one way through which groups reify their social identities, then intermarriage-or marriage with someone outside one's own ethnic group-indicates processes consistent with weakening one's own ethnic identity in favor of a broader national identity. At the same time, inter-ethnic marriages also reflect social acceptance of these groups in a way much deeper than words alone. In other words, intermarriage across ethnic groups represents the "final stage of assimilation" (Gordon 1964). Not only is marriage important as an expression of one's own social identity, but it also socializes future generations into particular world views (Bisin, Topa, and Verdier 2004; Davenport 2016). Among children with inter-ethnic marriages, we should then expect integration to persist through the intergenerational transmission of these weaker ethnic identities in favor of more national ones (Bisin and Verdier 2001; Bisin, Topa, and Verdier 2004). Finally in the context of the early 20th century United States, rates of inter-ethnic marriage were quite low reflecting the vast potential for military service to propagate cultural integration through marriage markets (Pagnini and Morgan 1990; Fryer 2007).

Naturalization: Citizenship is a key component of the political incorporation of groups in the United States (Smith 1999). Naturalization itself reflects both demand from the immigrant's perspective and the dominant group's willingness to accept that immigrant into society. Not only does citizenship represent state-sanctioned political integration, but it can also be a catalyst 
for further political and social integration (Hainmueller, Hangartner, and Pietrantuono 2015, 2017). Given the importance of naturalization in the overall process of integration, I create an indicator from the 1930 U.S. Census reflecting whether an immigrant male was a naturalized citizen.

Naming Conventions: Names, to varying degrees, reflect social identities. A large literature uses individuals' names to produce more fine-grained measures of integration (Sue and Telles 2007; Abramitzky, Boustan, and Eriksson 2014; Fouka 2019b, 2019a; Abramitzky, Boustan, and Eriksson 2017). The use of names essentially measures parents preferences over a vector of social identities that they could choose to express through their children. By using names as a proxy for cultural integration, one can understand variation in preferences over identity across ethnic groups and within ethnic groups since some names are considered more "American" than others despite (i.e, Josef vs. Joseph). Not only are names consequential in terms of measuring a parent's efforts at assimilating their children into a dominant culture, but also because the character of one's name can shape employment prospects and experiences with the state (Bertrand and Mullainathan 2004; Pager 2007; White, Nathan, and Faller 2015; Abramitzky, Boustan, and Eriksson 2017). To operationalize this, I compute the American Name Index (ANI) for each individual's $i$ of birth cohort $b$ and sex $s$ for their spouse and children where larger values reflect more "American" names. :

$$
A N I_{i, b, s}=100 \times \frac{P\left(\text { Name }_{i, b, s} \mid \text { Native-born }_{b, s}\right)}{P\left(\text { Name }_{i, b, s} \mid \text { Native-born }_{b, s}\right)+P\left(\text { Name }_{i, b, s} \mid \text { Foreign-Born }_{b, s}\right)}
$$

\section{Empirical Strategy 1: Selection-on-Observables}

First, I pursue an OLS estimation strategy that uses a "selection-on-observables" assumption to recover the causal effect of military service during WWI on the integration of immigrants. The key assumption behind this empirical strategy is that, conditional on observable characteristics, 
military service should be plausibly exogenous. To make this assumption tenable, I include fixed effects for birth year, year of immigration, ethnic group, and county. Thus, this strategy assumes that within birth year, year of immigration, ethnic group, and county, military service is seemingly exogenous.

A key threat to this empirical strategy is that immigrants might voluntarily enlist in the military because they already feel assimilated to begin with. If this is the case, then a strategy that relies on a conditional exogeneity assumption would be upward biased. It could also be, however, that the social returns to military service in terms of status and prestige could actually lead those who are most discriminated against to begin with to enlist in the military as a way to improve their social standing. Empirically, Fouka (2019b) shows that immigrants who are more discriminated against tend to be more likely to enlist in the military. This selection process suggests that this strategy would be downward biased instead. Thus, it is important to ensure that the results are insensitive to deviations from the selection-on-observables assumption no matter which direction the bias goes. As a result, I also use a formal sensitivity analysis of this assumption and show that the results are robust to even large deviations from the core identifying assumption.

With this strategy, I estimate equations of the following form in the overall sample of firstgeneration males in addition to subgroup analysis across the Irish, Italians, Eastern Europeans, and Germans:

$$
Y_{i, e, b, c, y r}=\beta \operatorname{Vet}_{i, e, b, c, y r}+\Lambda E_{e}+\Gamma B_{b}+\Theta C_{c}+\Omega Y r_{y r}+\epsilon_{i, e, b, c, y r}
$$

The key coefficient of interest is $\beta$, which represents the difference in means between WWI veterans versus non-veterans on outcome $Y$ (marriage with native-born and naturalization). To flexibly account for observable factors, I include fixed effects for ethnic group $\Lambda E_{e}$, birth cohort $\Gamma B_{b}$, county $\Theta C_{c}$, and year of arrival to the U.S. $\Omega Y r_{y r}{ }^{4}$ Thus, all comparisons are

\footnotetext{
${ }^{4}$ Ethnic groups are defined as Irish, Italian, Eastern European/Russian, German, and other
} 
within ethnic group, birth cohort, county, and year of arrival. Finally, $\epsilon_{i, e, b, c, y r}$ represents a population error term with standard errors on coefficients corrected for heteroskedasticity.

\section{OLS Results}

Table 1: Effect of WWI Veteran Status on Cultural Assimilation: OLS

\begin{tabular}{lcc}
\hline & Spouse Native-Born & Naturalized \\
& $(1)$ & $(2)$ \\
\hline WWI Veteran & $0.147^{* * *}$ & $0.251^{* * *}$ \\
& $(0.001)$ & $(0.001)$ \\
Birth Year Fixed Effects & $\checkmark$ & $\checkmark$ \\
Year of Immigration Fixed Effects & $\checkmark$ & $\checkmark$ \\
Ethnicity Fixed Effects & $\checkmark$ & $\checkmark$ \\
County Fixed Effects & $\checkmark$ & $\checkmark$ \\
Ctrl. Group Mean & 0.28 & 0.564 \\
$\mathrm{~N}$ & $4,899,393$ & $7,754,857$ \\
\hline${ }^{*} \mathrm{p}<.1 ;{ }^{* *} \mathrm{p}<.05 ;{ }^{* * *} \mathrm{p}<.01$ & &
\end{tabular}

Heteroskedastic robust standard errors in parentheses.

Does military service induce immigrant men to integrate into white American society? If so, how large were these effects? To begin, I first examine the effect of war service and integration using OLS in Table 1. Across both native-born intermarriage as well as naturalization, I find strong evidence suggesting that military veterans were more likely to integrate into American society relative to non-veterans. Starting with Column 1, which displays the coefficient on marriage-a proxy for social integration, I find that WWI veterans are approximately $15 \%$ more likely to marry someone who is native-born. Substantively, this represents a 53 percentage point change above the control group mean. Moving to Column 2, which displays the coefficient on naturalization-a proxy for political integration, I find that WWI veterans are approximately (baseline category). 
$25 \%$ more likely to become naturalized citizens relative to non-veterans. In substantive terms, this estimate reflects a 44 percentage point change above the control group mean. Thus, these results suggest that military service during WWI seemed to have been a powerful assimilating agent during this time period.

To ensure that these results are not the product of a statistical artifact or dependent on the assumption that there are no unobserved confounders, I employ a number of robustness checks. First, I show that the results are robust to estimation strategy by using matching estimation via exact matching, coarsened exact matching (Iacus, King, and Porro 2012), and sub-classification (Figure A1-4). Next, I also show that the results are robust to choice of control variables (Tables A1-2,A1-4, and A1-3). I also show that the results are robust to clustering standard errors by birth year (Table A1-5). Additionally, I show that the results are robust to trimming the sample to only include individuals from birth cohorts with a non-zero probability of serving in the military to reduce model dependence issues (Table A1-6). Finally and perhaps most importantly, I also show that the results are robust to the key identifying assumption in this empirical strategy-that WWI service is plausibly exogenous conditional on ethnic group, birth year, year of immigration, and county fixed effects (Figure A1-5). Details on these robustness checks can be found in the Supplementary Appendix.

One important component to separate is the role of immigrant effort from native-born acceptance. To do so, I rely on the $A N I$ outcome described above for an individual's spouse and children. These outcomes, to a greater degree than the measures presented so far, represent the effort that an immigrant tries to exert in shaping the expression of his social identity. The results, presented in Table 2, show that immigrant men who served are more likely to marry women and name their children with more "American" sounding names. Substantively, the results for children suggest that military service is equivalent from moving from a "Jewish" sounding name 
Table 2: Effect of WWI Veteran Status on Naming Patterns: OLS

\begin{tabular}{lcc}
\hline & Spouse ANI & Avg. Children's ANI \\
& $(1)$ & $(2)$ \\
\hline WWI Veteran & $1.620^{* * *}$ & $2.135^{* * *}$ \\
& $(0.036)$ & $(0.028)$ \\
Birth Year Fixed Effects & $\checkmark$ & $\checkmark$ \\
Year of Immigration Fixed Effects & $\checkmark$ & $\checkmark$ \\
Ethnicity Fixed Effects & $\checkmark$ & $\checkmark$ \\
County Fixed Effects & $\checkmark$ & $4,905,723$ \\
N & $4,445,771$ & \\
\hline${ }^{*} \mathrm{p}<.1 ;{ }^{* *} \mathrm{p}<.05 ;{ }^{* * *} \mathrm{p}<.01$ & & \\
Heteroskedastic robust standard errors in parentheses.
\end{tabular}

like Moische to a more "American" version like Morris. These results demonstrate at least some role for immigrant effort and not just the fact that native-born individuals are more willing to accept immigrant veterans into their communities.

\section{Empirical Strategy 2: Instrumental Variables}

Despite there being a draft for much of the United States' involvement in the war, there were still a great deal of individuals who chose to volunteer for the war effort. Since there was still an element of choice into whether men decided to join, this could induce bias if the individuals who chose to join were systematically different than men who did not volunteer. A simple regression of proxies for cultural integration on military service could just pick up on immigrant, men who already were more inclined to assimilate in the first place since they chose to risk their life for the United States. As a result, any estimates would pick up latent, unobservable characteristics about these men and not necessarily the counter-factual effect of what these men would have done had they not served. Though the above results do not seem to be sensitive to this assumption, nevertheless I pursue an alternate empirical strategy: instrumental variables.

To facilitate causal inferences, I focus on a specific type of variation in military service that 
Figure 2: Likelihood of WWI Service among Immigrant, Males by Birth Cohort

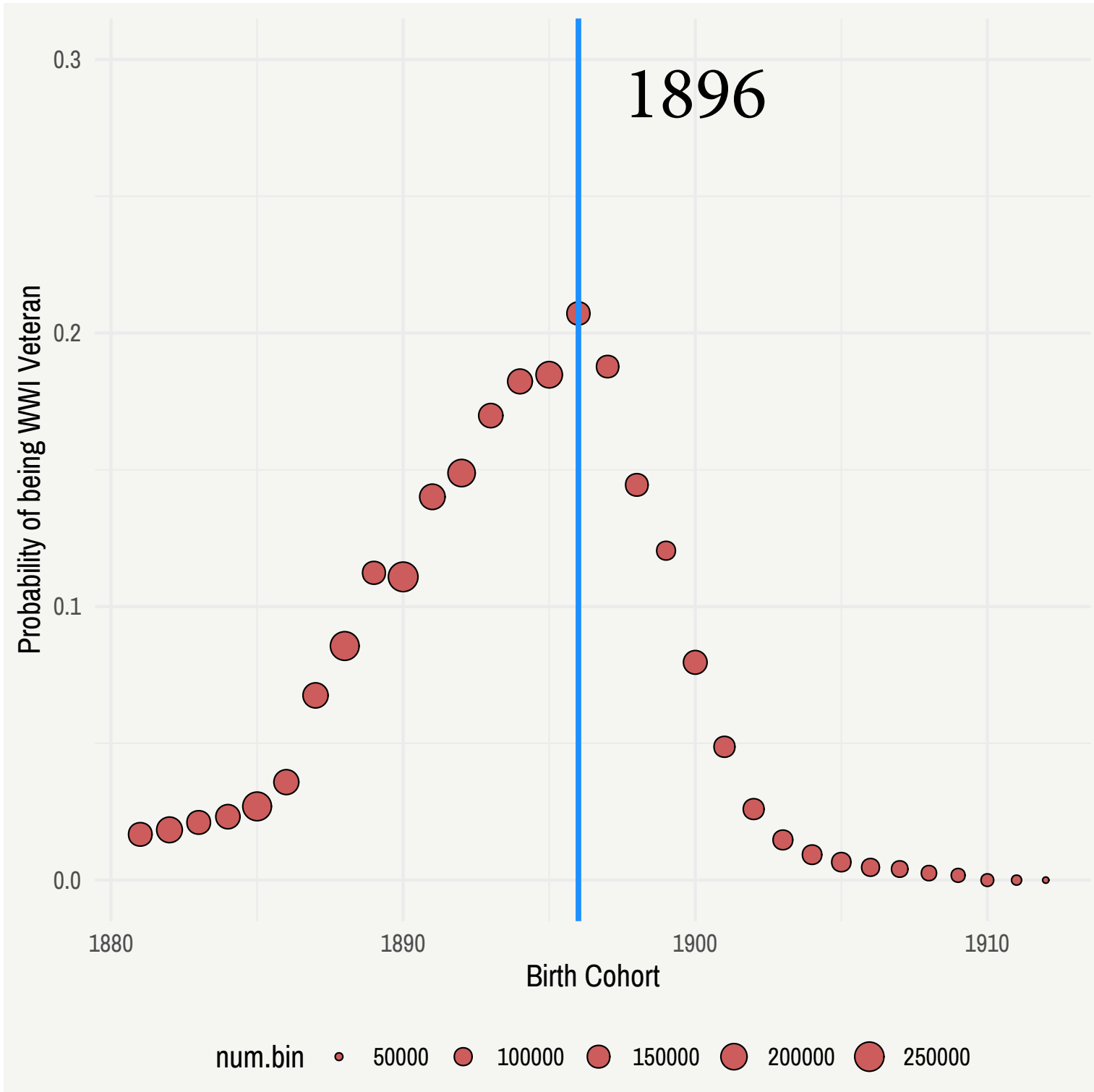

Source: 1930 Census accessed through IPUMS. Size of the circles correspond to the number of individuals in each bin. 
is largely exogenous with respect to the aforementioned factors: the interaction of an individuals birth cohort/age with features of the draft system and general physical suitability for war service. President Woodrow Wilson only reluctantly entered the U.S. into the conflict after the escalation of unrestricted submarine warfare by the Germans in addition to the revelation of the Zimmerman Telegram in which the German Foreign Ambassador attempted to create an alliance between Germany and Mexico. These events essentially forced Wilson's hand leading the exact timing of the U.S.'s entry into the war to be exogenous. Building on Campante and Yanagizawa-Drott (2016), I utilize an idiosyncratic feature of cohort variation in war service brought on by the imposition of a draft and the fact that most males tend to be in their prime physical shape in their 20 s. Figure 2 plots the probability that an immigrant, male served as a veteran by the year of birth. Two clear patterns emerges: (1) there is a marked symmetry centered around individuals born in 1896 (those who were 21 during the midpoint of the war) and (2) that this likelihood of war service peaks for those individuals born in 1896 who were thus 21 years old during the midpoint of WWI. I exploit this unique feature of war mobilization-the symmetry around the peak service likelihood at the age of 21-as a plausibly exogenous encouragement into war service (Campante and Yanagizawa-Drott 2016). Concretely, this intuition can be captured by taking the absolute value of an individual's birth year from 1896-the cohort who would have been twenty-one during the war. The use of the absolute value from 1896 ensures that I am not simply capturing the fact that older men might be more or less likely to serve; rather, nineteen and twenty-three year olds during the war are "encouraged" exactly the same. Because of both the timing of the war with respect to an individual's age, one can use this plausibly exogenous variation as an instrumental variable.

The validity of this design also depends on several other assumptions-some that can be tested and others that cannot (Angrist and Pischke 2009). First, the instrument must be rele- 
Table 3: First-Stage Relationship between Distance to 21 and WWI Veteran Status

\begin{tabular}{lccccc}
\hline & \multicolumn{5}{c}{ WWI Veteran } \\
& $(1)$ & $(2)$ & $(3)$ & $(4)$ & $(5)$ \\
\hline Distance to 21 during War & $-0.013^{* * *}$ & $-0.022^{* * *}$ & $-0.028^{* * *}$ & $-0.028^{* * *}$ & $-0.028^{* * *}$ \\
& $(0.001)$ & $(0.002)$ & $(0.003)$ & $(0.003)$ & $(0.002)$ \\
Birth Year Quadratic & & $\checkmark$ & $\checkmark$ & $\checkmark$ & $\checkmark$ \\
Ethnicity Fixed Effects & $\checkmark$ & $\checkmark$ & $\checkmark$ & $\checkmark$ \\
State Fixed Effects & & $\checkmark$ & & $\checkmark$ \\
County Fixed Effects & & & & $\checkmark$ \\
Year of Immigration Fixed Effects & & & & \\
$\mathrm{N}$ & $4,740,806$ & $4,740,806$ & $4,740,806$ & $4,740,806$ & $4,740,806$ \\
Adjusted $\mathrm{R}^{2}$ & 0.047 & 0.056 & 0.059 & 0.063 & 0.073 \\
\hline${ }^{*} \mathrm{p}<.1 ;{ }^{* *} \mathrm{p}<.05 ;{ }^{* * *} \mathrm{p}<.01$ & & & & \\
Standard errors clustered by birth year in parentheses. &
\end{tabular}

vant in that it has a non-zero causal effect on war service. Given the exogeneity of the instrument, one can test this assumption by examining the first-stage relationship using Ordinary Least Squares (OLS). Table 3 shows that there is a strong and statistically significant relationship between an immigrant's distance to being 21 during the war and his likelihood of serving in WWI. On average, an additional year of being closer to 21 during the war increases an individual's propensity to serve in the war by approximately one percent. Given that the average mobilization rate nationally was around eight percent, this is substantively quite large. Additionally, these results are robust across a wide array of specifications including specifications with state by birth cohort trends and even county by birth cohort trends. The coefficient on the instrument remains virtually unchanged across all of these specifications yielding strong evidence consistent with the exogeneity assumption stemming from the timing of the war (Altonji, Elder, and Taber 2005).

Next, this design must also satisfy the Stable Unit Treatment Value Assumption (SUTVA). This assumption states that there can be no interference among units and that war service is comparable across individuals. Since birth years are largely independent of other units, this context likely satisfies SUTVA. Moreover, the instrumental variables design must also satisfy 
a monotonicity assumption in that being closer to turning 21 should not induce individuals to become less likely to serve in the war. The main threat to this assumption would come from the possibility of draft dodging. At least according to the historical literature, there seems to be very little evidence that this practice was prevalent suggesting that it is also likely the case that this setting satisfies monotonicity. Finally, the validity of this design hinges on an exclusion restriction whereby distance to being 21 during the middle of the war can only affect cultural integration through military service. A threat to this assumption would occur if there were some other life event that happens as individuals get closer to 21 during the middle of WWI. The only other major political change that could happen is becoming eligible to vote. Given the historical context, there is little evidence to support the notion that becoming eligible to vote in elections should lead to cultural integration. The 1918 election was not a major presidential election and cultural integration was not an election issue at the time. Another potential violation could come from labor market experiences. Again for this to violate the exclusion restriction, any labor market induced integration must have been symmetric around 21. Since there are no formal requirements to be 21 to work during that time, this channel does not seem to significantly threaten this design. Importantly, I use a placebo test and bias-correction method to more directly address the plausibility of this assumption and its impact on the results. Thus, the proposed instrument-distance to being 21 during the middle of the war in 1918-seemingly satisfies these key assumptions needed for this design to recover the Local Average Treatment Effect (LATE).

With these outcomes and identification strategy, I proceed to estimate regressions of the following form using two-stage least squares (2SLS):

$$
\operatorname{Vet}_{i, e, b, c, y r}=\pi|\operatorname{BirthYr}-1896|_{i, e, c, y r}+\Gamma X_{i, b}+\Lambda E_{e}+\Theta C_{c}+\Omega Y r_{y r}+\eta_{i, e, b, c, y r}
$$




$$
Y_{i, e, b, c, y r}=\beta \widehat{\mathrm{Vet}}_{i, e, c, y r}+\Gamma X_{i, b}+\Lambda E_{e}+\Theta C_{c}+\Omega Y r_{y r}+\epsilon_{i, e, b, c, y r}
$$

Again, the coefficient $\beta$ represents the LATE of $\operatorname{Vet}_{i, e, c, y r}$ on the aforementioned measures of integration $Y$.

The coefficient $\pi$ represents the first-stage effect of $\mid$ BirthYr $-\left.1896\right|_{i, e, c, y r}$ on the likelihood that an immigrant served in World War I. Importantly, Table 3 shows that the instrument is quite strong with the F-statistic well above the suggested value of 10 (Stock and Yogo 2005). Moreover, the term $X_{i}$ controls for birth year quadratically to capture any secular trends over time. ${ }^{5}$ Again, I also include a series of ethnic group fixed effects $\Lambda E_{e}$ for Germans, Irish, Italians, and Eastern Europeans such that all comparisons are made between individuals of the same ethnic group. Next, I include fixed effects for counties $\Theta C_{c}$ such that comparisons are made between individuals living in the same county. ${ }^{6}$ I also include year of arrival fixed effects $\Omega Y r_{y r}$. I cluster standard errors at the birth cohort level though the inferences are robust to using heteroskedastic robust standard errors as well. Finally, to help make the exogeneity assumption more plausible, I also truncate the sample to males born between 1880 and 1913those individuals who would have had a significant likelihood of actually being moved to serve by the instrument. ${ }^{7}$

Table 4 again shows strong support for the causal impact of WWI service on immigrant integration. Both outcomes remain substantively significant, though the standard errors become

\footnotetext{
${ }^{5}$ I cannot include birth year fixed effects because they are perfectly collinear with the in-
} strument.

${ }^{6}$ One potential issue is that individuals could have moved counties upon returning from the war, which would induce post-treatment bias. The results are robust to using state fixed effects and not including any geographic unit fixed effects.

${ }^{7}$ The results are robust to trimming cohorts on either side as well. 
Table 4: Effect of WWI Veteran Status on Cultural Assimilation: Two-Stage Least Squares

\begin{tabular}{lcc}
\hline & Spouse Native-Born & Naturalized \\
& $(1)$ & $(2)$ \\
\hline WWI Veteran & $0.091^{* *}$ & $0.343^{* * *}$ \\
& $(0.040)$ & $(0.044)$ \\
Birth Year Quadratic & $\checkmark$ & $\checkmark$ \\
Year of Immigration Fixed Effects & $\checkmark$ & $\checkmark$ \\
Ethnicity Fixed Effects & $\checkmark$ & $\checkmark$ \\
County Fixed Effects & $\checkmark$ & $\checkmark$ \\
$\mathrm{N}$ & $3,029,552$ & $4,740,806$ \\
\hline${ }^{*} \mathrm{p}<.1 ;{ }^{* *} \mathrm{p}<.05 ;{ }^{* * *} \mathrm{p}<.01$ & & \\
Standard errors clustered by birth year in parentheses. &
\end{tabular}

much larger due to clustering of outcomes at the birth cohort level. These results, again, are robust to the inclusion of various fixed effects and to trimming cohorts who were younger than 16 during WWI from the sample. In short, the instrumental variables results seem to confirm the OLS results presented above.

One core assumption behind the validity of this empirical strategy is the exclusion restrictionthat distance to being born in 1896 only affects integration through military service. To help guard against potential biases from violations of this assumption, it is important to conduct placebo tests to check the validity of this core assumption. A good placebo in this case should be of a similar type of sample to the main 2SLS sample, but differ in that it does not have access to the treatment of interest-in this case, military service for the U.S. As such, I conduct a placebo test using first-generation immigrants who observationally look identical to the main IV sample, but happened to arrive to the U.S. after WWI ended in 1919. These individuals, ostensibly, should not have access to becoming a veteran of the U.S. during WWI. If there were to be an exclusion restriction violation, then the direct effect of distance to being born in 1896 among this placebo sample must be significantly different from zero. One can go even further and take the estimated direct effect in the placebo sample and use it to subtract off and 
"bias-correct" the main 2SLS estimates (Conley, Hansen, and Rossi 2012). This bias-corrected estimate, then, represents the LATE of military service net of exclusion restriction violations.

Table 5: Effect of WWI Veteran Status on Cultural Assimilation: Two-Stage Least Squares (BiasCorrected Estimates)

\begin{tabular}{lcccc}
\hline & $\begin{array}{c}\text { Spouse Native-Born } \\
\text { Naturalized }\end{array}$ & $\begin{array}{c}\text { Spouse Native-Born (Bias Corrected) } \\
(1)\end{array}$ & $\begin{array}{c}\text { Naturalized (Bias Corrected) } \\
(4)\end{array}$ \\
\hline Distance to 21 & $0.007^{* * *}$ & $-0.005^{* * *}$ & & \\
& $(0.002)$ & $(0.001)$ & & $0.170^{* * *}$ \\
WWI Veteran & & & $0.322^{* * *}$ & $(0.045)$ \\
& & $\checkmark$ & $\checkmark$ & $\checkmark$ \\
Birth Year Quadratic & $\checkmark$ & $\checkmark$ & $\checkmark$ & $\checkmark$ \\
Year of Immigration Fixed Effects & $\checkmark$ & $\checkmark$ & $\checkmark$ & $\checkmark$ \\
Ethnicity Fixed Effects & $\checkmark$ & $\checkmark$ & $3,029,552$ & $4,740,806$ \\
County Fixed Effects & $\checkmark$ & & \\
$\mathrm{N}$ & 615,250 & $1,348,535$ & &
\end{tabular}

Table 5 shows the results of this sensitivity analysis. Column 1 of Table 5 indicates that, if anything, exclusion restriction violations are inducing downward bias into the 2SLS estimates since individuals closer to being born in 1896 in the placebo sample are actually less likely to marry a native-born spouse. Column 3 of Table 5 uses this estimate to bias-correct the original 2SLS estimates again leaving the results to be stronger. Column 2 of Table 5 shows a slight potential for an exclusion restriction violation that puts upward bias into the original 2SLS, though the magnitude is quite small. Applying the bias-correction procedure in Column 4, the results still remain robust to deviations from the exclusion restriction suggested by the placebo test. In short, these results indicate that the results are insensitive to reasonable violations of the exclusion restriction suggesting that there is indeed a causal effect of military service on integration.

Probing Mechanisms 


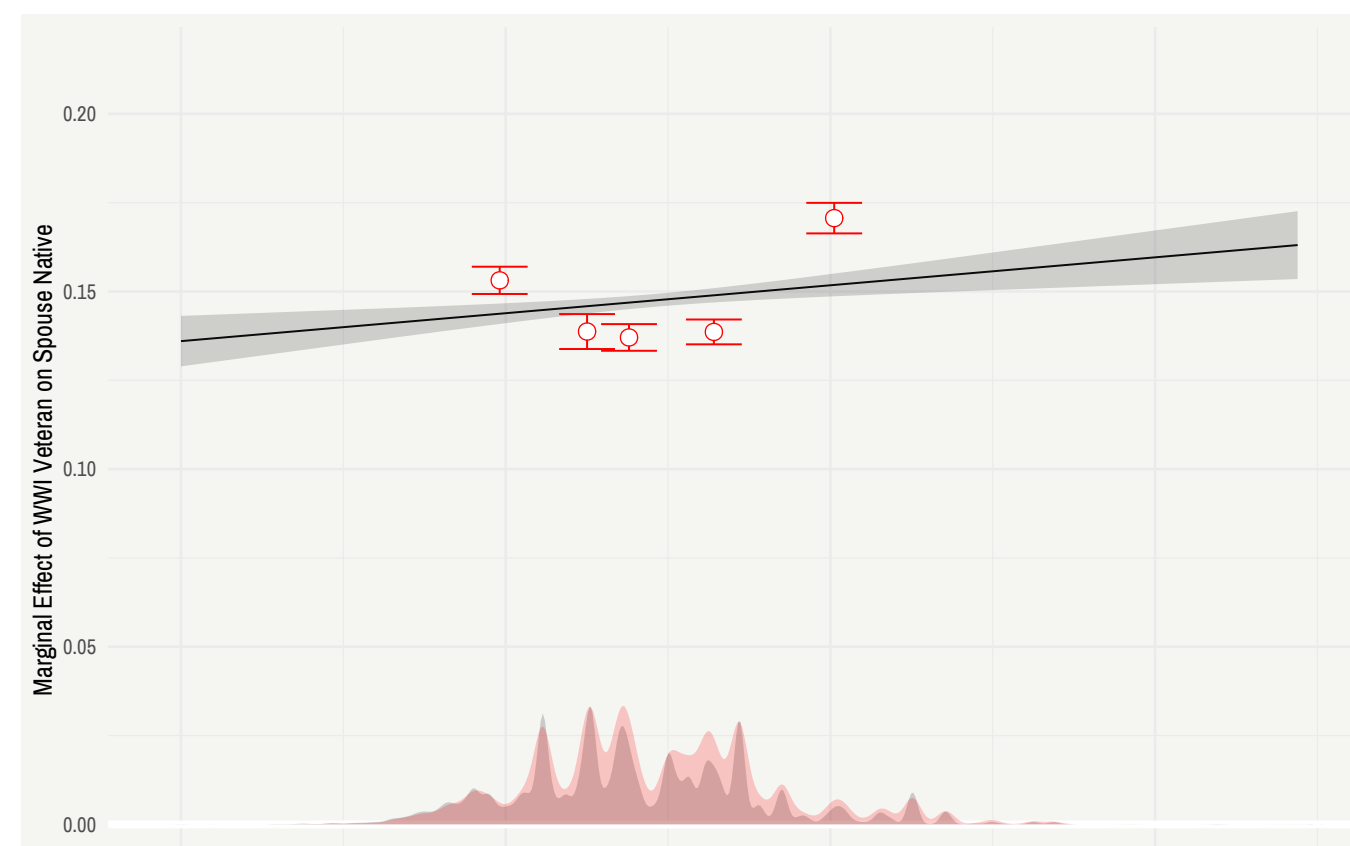

0.00
0.05 Moderator: Prop. Vet (Native-born)

0.15

(a) Spouse Native-Born
0.3

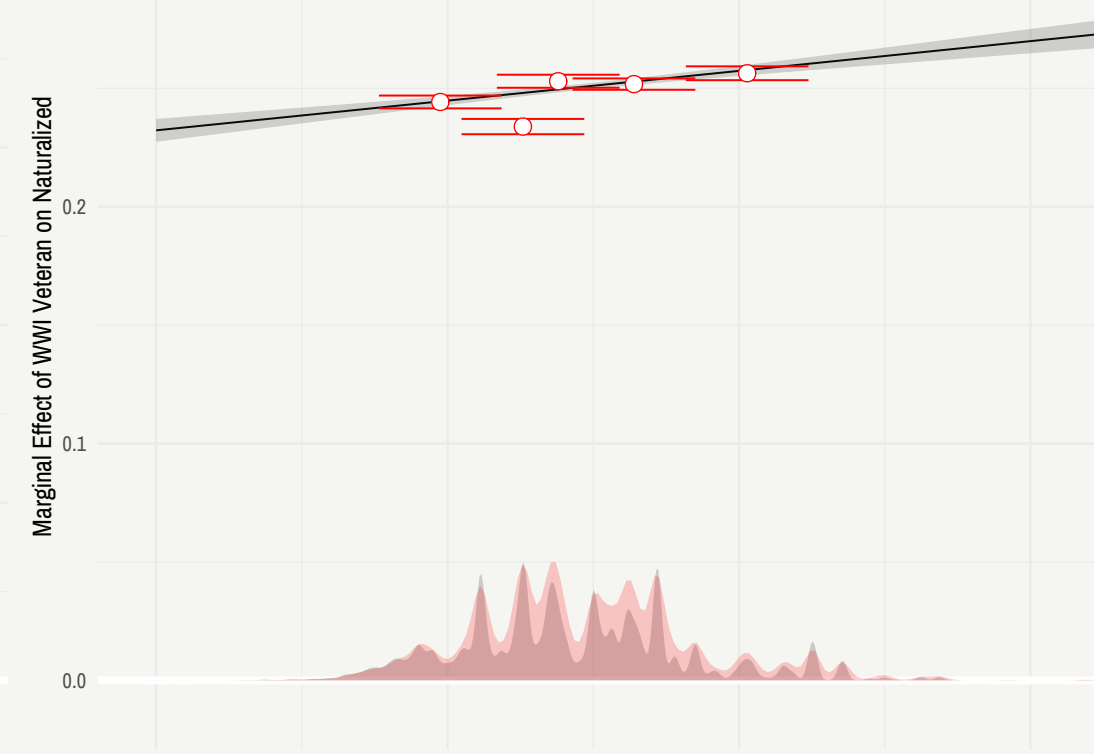

Moderator: Prop. Vet (Native-born)

(b) Naturalization

Figure 3: Effect Moderation by County Prop. of Veterans Who Are Native-Born 
Thus far, the analysis shows robust support for the effect of military service on immigrant integration. To further validate the argument developed in this paper, I investigate the role of wartime social networks as one potential mechanism of military-led socialization into American culture. I investigate heterogeneity of the impact of military service by the proportion of veterans who are native-born in a given immigrant's county of residence in 1930. Given the importance of organizations such as veterans associations in facilitating social bonds among their members (Skocpol, Ganz, and Munson 2000), this exercise then captures the degree to which immigrant veteran's access to these social networks might contribute to their increased ability to integrate.

The results, shown in Figure 3, suggest that the effect of military service on immigrant integration is increasing in the proportion of native-born veterans in that immigrant's county. Importantly, though, these results also suggest that these social networks are not sufficient on their own to explain the findings. Even among immigrants residing in areas with low access to native-born veterans, the effect of military service is still positive and statistically significant. In short, these results provide some support for the importance of these wartime social networks in addition to leaving some scope for the other mechanisms described in this article such as inculcation in the military. Future research, then, should aim to find settings that are better able to arbitrate among these mechanisms.

\section{CONCLUSION}

The theory and results provide further evidence of the powerful force of mass warfare in the creation of political order, democracy, and equality (Tilly 1990; Scheve and Stasavage 2012; Ferejohn and Rosenbluth 2016). While the vast majority of studies in this tradition emphasize the role that warfare has on our political institutions, I provide a theory in which warfare can fundamentally reshape our social identities. This idea is related to the broader notion that mass 
mobilization can change the ideological context of a nation. For example, Klinkner and Smith (1999) recount how World War II shifted ideas about the compatibility of democracy and the Jim Crow system of racial discrimination in the United States. While these studies tend to highlight the broader ideological changes that come with mass warfare, this paper highlights the incredibly personal way in which participation in mass warfare can reshape who we are.

This paper also has important implications for contemporary debates about the way in which liberal societies can incorporate immigrants. Though scholars have convincingly shown that immigrants face a massive degree of discrimination, we know much less about the factors that can help to incorporate immigrants (Hopkins 2010; Newman 2012; Fouka 2019a, 2019b; Fouka, Mazumder, and Tabellini 2019). Several recent studies show that the state can play an important role in facilitating immigrant incorporation. For example, Hainmueller, Hangartner, and Pietrantuono $(2015,2017)$ show that providing citizenship to immigrants increases their integration into society across political and social dimensions. At the same time, Hainmueller and Hangartner (2013) show that natives preferences over these immigrants play a strong role in determining which immigrants natives are willing to accept into their society. There are many factors that influence both an immigrant's willingness to assimilate and natives' willingness to accept an immigrant that shape the decision to naturalize. Instead, I show that participation in mass warfare can jointly affect both channels. Work by Mazumder (2019) shows that the rise of mass schooling had a limited role to play in shaping cultural integration in American history-an important finding to note given the extensive literature on the central role of mass education in shaping national identity. This suggests that future work should seek to better understand the conditions under which different types of state policies can successfully shift either immigrant or native values.

On a much broader note, this study, when viewed alongside the wider literature on the relationship between warfare and egalitarianism, raises a number of thorny normative questions. Are the status-leveling features of mass warfare compatible with the principles of liberal democ- 
racy especially when considering the mass violence and destruction associated with warfare? If warfare does actually lead to prodigious societal progress, what are the prospects for maintaining equality and reducing new inequalities in an age where nations no longer engage in mass warfare for normative and technological reasons? Obviously, there are no easy answers for these questions, but in an age where discrimination and inequality are now again on the rise, we must grapple with this irony of social progress. 


\section{References}

Abramitzky, Ran, Leah Platt Boustan, and Katherine Eriksson. 2014. "A Nation of Immigrants: Assimilation and Economic Outcomes in the Age of Mass Migration." Journal of Political Economy 122 (3): 467-517.

— . 2017. "Cultural Assimilation during the Age of Mass Migration." NBER Working Paper No. 22381. https://www . nber.org/papers/w22381.

— . 2012. "Europe's Tired, Poor, Huddled Masses: Self-Selection and Economic Outcomes in the Age of Mass Migration." American Economic Review 102 (5): 1832-1856.

Adida, Claire L., David D. Laitin, and Marie-Anne Valfort. 2016. Why Muslim Integration Fails in Christian-Heritage Societies. Harvard University Press.

Alford, John R., et al. 2011. “The Politics of Mate Choice.” Journal of Politics 73 (2): 362-379.

Allport, Gordon. 1954. The Nature of Prejudice. Addison-Wesley.

Altonji, Joseph G, Todd E Elder, and Christopher R Taber. 2005. “Selection on Observed and Unobserved Variables: Assessing the Effectiveness of Catholic Schools." Journal of Political Economy 113 (1): 151-184.

Anderson, Benedict. 1983. Imagined Communities: Reflections on the Origin and Spread of Nationalism. Verso.

Angrist, Joshua D, and Jorn-Steffen Pischke. 2009. Mostly Harmless Econometrics: An Empricists's Companion. Princeton University Press. 
Bensel, Richard Franklin. 1990. Yankee Leviathan: The Origins of Central State Authority in America, 1859-1877. Cambridge University Press.

Bertrand, Marianne, and Sendhil Mullainathan. 2004. "Are Emily and Greg More Employable Than Lakisha and Jamal? A Field Experiment on Labor Market Discrimination.” American Economic Review 94 (4): 991-1013.

Bisin, Alberto, Giorgio Topa, and Thierry Verdier. 2004. "Religious Intermarriage and Socialization in the United States." Journal of Political Economy 112 (3): 615-664.

Bisin, Alberto, and Thierry Verdier. 2001. "The Economics of Cultural Transmission and the Dynamics of Preferences." Journal of Economic Theory 97:298-319.

Campante, Filipe, and David Yanagizawa-Drott. 2016. “The Intergenerational Transmission of War." Working Paper. https : / / www . google . com / url ? q=https $\% 3 \mathrm{~A} \% 2 \mathrm{~F} \% 2 \mathrm{Fwww}$. dropbox.com\%2Fs\%2Fl8bcacuhgc7oow1\%2FCYD_ITOW_Oct2016.pdf\%3Fraw\%3D1\& sa=D\&sntz=1\&usg=AFQjCNFTQVOmM94-XjCBMHyup08bwkUxjQ.

Conley, Timothy G., Christian B. Hansen, and Peter E. Rossi. 2012. “Plausibly Exogenous.” Review of Economics and Statistics 94 (1): 260-272.

Costa, Dora L., and Matthew E. Kahn. 2008. Heroes and Cowards: The Social Faces of War. Princeton University Press.

Davenport, Lauren D. 2016. "Beyond Black and White: Biracial Attitudes in Contemporary U.S. Politics." American Political Science Review 110 (1): 52-67.

Ferejohn, John A., and Frances McCall Rosenbluth. 2016. Forged through Fire: War, Peace, and the Democratic Bargain. Liveright.

Flemming, Ralston. 1918. “Ralston Flemming to Joseph Tumulty, September, 9, 2018.” In Woodrow Wilson Papers. Library of Congress Manuscript Division. https : / / www . loc . gov / 
exhibitions / world - war - i - american - experiences / online-exhibition / over-here/americanization/enthusiastic-americanism/?loclr=blogloc.

Fouka, Vasiliki. 2019a. “Backlash: The Unintended Effects of Language Prohibition in US Schools after World War I." Review of Economic Studies.

— . 2019b. "How Do Immigrants Respond to Discrimination? The Case of Germans in the US during World War I." American Political Science Review 113 (2): 405-422.

Fouka, Vasiliki, Soumyajit Mazumder, and Marco Tabellini. 2019. "From Immigrants to Americans: Race and Assimilation during the Great Migration.” Working Paper. https : //doi . org/10.31219/osf .io/eka5y.

Fryer, Roland G. 2007. “Guess Who's Coming to Dinner? Trends in Interracial Marriage over the 20th Century." Journal of Economic Perspectives 21 (2): 71-90.

Gellner, Ernest. 1983. Nations and Nationalism. Cornell University Press.

Gordon, Milton M. 1964. Assimilation in American Life: The Role of Race, Religion and National Origins. Oxford University Press.

Hainmueller, Jens, and Dominik Hangartner. 2013. "Who Gets a Swiss Passport? A Natural Experiment in Immigrant Discrimination.” American Political Science Review 107 (1): 159187.

Hainmueller, Jens, Dominik Hangartner, and Giuseppe Pietrantuono. 2017. “Catalyst or Crown: Does Naturalization Promote the Long-Term Social Integration of Immigrants?” American Political Science Review 111 (2): 256-276.

— . 2015. "Naturalization Fosters the Long-Term Political Integration of Immigrants." Science 112 (41): 12651-12656. 
Hainmueller, Jens, Jonathan Mummolo, and Yiqing Xu. 2019. "How Much Should We Trust Estimates from Multiplicative Interaction Models? Simple Tools to Improve Empirical Practice." Political Analysis 27 (2): 163-192.

Harder, Niklas, et al. 2018. "Multidimensional Measure of Immigrant Integration.” Proceedings of the National Academy of Science 115 (45): 11483-11488.

Hobsbawm, Eric. 1990. Nations and Nationalism Since 1780. Cambridge University Press.

Hochschild, Jennifer L., and Brenna Marea Powell. 2008. "Racial Reorganization and the United States Census 1850-1930: Mulattoes, Half-Breeds, Mixed Parentage, Hindoos, and the Mexican Race." Studies in American Political Development 22 (1): 59-96.

Hopkins, Daniel J. 2010. "Politicized Places: Explaining Where and When Immigrants Provoke Local Opposition.” American Political Science Review 104 (1): 40-60.

Huber, Gregory, and Neil Malhotra. 2016. "Political Homophily in Social Relationships: Evidence form Online Dating Behavior." Journal of Politics 79 (1): 269-283.

Iacus, Stefano M., Gary King, and Giuseppe Porro. 2012. “Causal Inference without Balance Checking: Coarsened Exact Matching." Political Analysis 20 (1): 1-24.

Ignatiev, Noel. 1995. How the Irish Became White. Routledge.

Kalmoe, Nathan P., and Kimberly Gross. 2016. "Cueing Patriotism, Prejudice, and Partisanship in the Age of Obama: Experimental Tests of U.S. Flag Imagery Effects in Presidential Elections." Political Psychology 37 (6): 883-899.

Katznelson, Ira. 2014. Fear Itself: The New Deal and the Origins of Our Time. Liveright.

King, Desmond S. 2000. Making Americans: Immigration, Race, and the Origins of the Diverse Democracy. Harvard University Press.

Klinkner, Philip A., and Rogers M. Smith. 1999. The Unsteady March: The Rise and Decline of Racial Equality in America. University of Chicago Press. 
Krebs, Ronald R. 2006. Fighting for Rights: Military Service and the Politics of Citizenship. Cornell University Press.

Laitin, David D. 1992. Language Repertoires and State Construction in Africa. Cambridge University Press.

Levendusky, Matthew. Forthcoming. “Americans, Not Partisans: Can Priming American National Identity Reduce Affective Polarization?" Journal of Politics.

Levi, Margaret. 1997. Consent, Dissent, and Patriotism. Cambridge University Press.

Lieberman, Evan S., and Prerna Singh. 2017. "Census Enumeration and Group Conflict: A Global Analysis of the Consequences of Counting." World Politics 69 (1): 1-53.

Marx, Anthony W. 1997. Making Race and Nation: A Comparison of South Africa, the United States, and Brazil. Cambridge University Press.

Mazumder, Soumyajit. 2019. "No Nation Left Behind? Historical and Quasi-Experimental Evidence on Hobsbawm’s Hypothesis." Working Paper. https : //doi .org/10.31235/osf . io/k687f.

Newman, Benjamin J. 2012. “Acculturating Contexts and Anglo Opposition to Immigration in the United States." American Journal of Political Science 57 (2): 374-390.

Pager, Devah. 2007. Marked: Race, Crime, and Finding Work in an Era of Mass Incarceration. University of Chicago Press.

Pagnini, Deanna L., and S. Philip Morgan. 1990. "Intermarriage and Social Distance among U.S. Immigrants at the Turn of the Century." American Journal of Sociology 96 (2): 405-432.

Parker, Christopher S. 2010. Fighting for Democracy: Black Veterans and the Struggle Against White Supremacy in the Postwar South. Princeton University Press.

Parkinson, Sarah Elizabeth. 2013. “Organizing Rebellion: Rethinking High-Risk Mobilization and Social Networks in War." American Political Science Review 107 (3): 418-432. 
Roediger, David. 1999. The Wages of Whiteness: Race and the Making of the American Working Class. Verso.

Sambanis, Nicholas, Stergios Skaperdas, and William C. Wohlforth. 2015. "Nation-Building through War.” American Political Science Review 109 (2): 279-296.

Samii, Cyrus. 2013. "Perils or Promise of Ethnic Integration? Evidence from a Hard Case in Burundi." American Political Science Review 107 (3): 558-573.

Scheve, Kenneth, and David Stasavage. 2012. "Democracy, War, and Wealth: Lessons from Two Centuries of Inheritance Taxation.” American Political Science Review 106 (1): 81-102.

- .2016. Taxing the Rich: A History of Fiscal Fairness in the United States and Europe. Princeton University Press / the Russell Sage Foundation.

Skocpol, Theda, Marshall Ganz, and Ziad Munson. 2000. “A Nation of Organizers: The Instituitonal Origins of Civic Voluntarism in the United States." American Political Science Review 94 (3): 527-546.

Smith, Rogers M. 1999. Civic Ideals: Conflicting Visions of Citizenship in U.S. History. Yale University Press.

Sterba, Christopher M. 2003. Good Americans: Italian and Jewish Immigrants during the First World War. Oxford University Press.

Stock, James H., and Motohiro Yogo. 2005. "Identification and Inference for Econometric Models." Chap. Testing for Weak Instruments in Linear IV Regression, ed. by Donald W.K. Andrews and James H. Stock. 5. Cambridge University Press.

Sue, Christina A., and Edward E. Telles. 2007. “Assimilation and Gender in Naming." American Journal of Sociology 112 (5): 1383-1415.

Tilly, Charles. 1990. Coercion, Capital, and European States, AD 990-1990. Blackwell. 
Weber, Eugen. 1976. Peasants into Frenchmen: The Modernization of Rural France, 1870-1914. Stanford University Press.

Weinstein, Jeremy M. 2006. Inside Rebellion: The Politics of Insurgent Violence. Cambridge University Press.

White, Ariel R., Noah L. Nathan, and Julie K. Faller. 2015. "What Do I Need to Vote? Bureaucratic Discretion and Discrimination by Local Election Officials." American Political Science Review 109 (1): 129-142.

Wilcox, Vanda. 2011. "Encountering Italy: Military Service and National Identity during the First World War." Bulletin of Italian Politics 3 (2): 283-302.

Wimmer, Andreas. 2017. "Power and Pride: National Identity and Ethnopolitical Inequality around the World." World Politics 69 (4): 605-639.

Wood, Elisabeth Jean. 2008. “The Social Processes of Civil War: The Wartime Transformation of Social Networks." Annual Review of Political Science 11:539-561.

Yanagizawa-Drott, David. 2014. "Propaganda and Conflict: Evidence from the Rwandan Genocide." Quarterly Journal of Economics 129 (4): 1947-1994. 
Online Appendix for "Becoming White:

How Military Service Turned Immigrants

into Americans" 


\section{Contents}

$\begin{array}{lll}\text { Contents } & \text { A1 }\end{array}$

Applying a Bias-Correction Procedure for Instrumental Variables . . . . . . . . . A2

Appendix: Summary Statistics . . . . . . . . . . . . . . . . . . . A3

Appendix: Robustness Checks and Additional Results . . . . . . . . . . . A5 


\section{APPLYING A BIAS-CORRECTION PROCEDURE FOR INSTRUMENTAL}

\section{VARIABLES}

To develop a bias-correction procedure for the exclusion restriction assumption needed for instrumental variables designs, I use the framework developed by Conley, Hansen, and Rossi (2012). Given the use of a continuous instrument in the paper, I follow the following two-stage least squares framework where we're interested in the causal effect of some regressor $X_{i}$ :

$$
\begin{gathered}
Y_{i}=\beta X_{i}+\gamma Z_{i}+\epsilon_{i} \\
X_{i}=\alpha Z_{i}+\eta_{i}
\end{gathered}
$$

The exclusion restriction in this setup is that $\gamma \equiv 0$. Deviations from this exclusion restriction suggest that $\gamma \neq 0$. Suppose that $\gamma \neq 0$, then we can rewrite the second-stage as follows and generate a new "bias-corrected" outcome $\widetilde{Y}_{i}$ :

$$
\widetilde{Y}_{i}=Y_{i}-\gamma Z_{i}=\beta X_{i}+\epsilon_{i}
$$

Since the exclusion restriction is an assumption in the IV sample, one needs a separate sample that is as close as possible to the IV sample, but without any access to the treatment $X_{i}$. This sets $\beta=0$ and further using the assumption that $\epsilon_{i} \sim N\left(0, \sigma^{2}\right)$, we can get a bias corrected $\tilde{Y}_{i}=Y_{i}-\gamma Z_{i}$ where $\gamma$ is estimated from the sample with no access to treatment. 


\section{APPENDIX: SUMMARY STATISTICS}

Summary Statistics

Table A1-1: Summary Statistics on Main Independent, Dependent, and Control Variables

\begin{tabular}{lccccc}
\hline \hline Statistic & $\mathrm{N}$ & Mean & St. Dev. & Min & Max \\
\hline WWI Veteran & $7,754,857$ & 0.052 & 0.222 & 0 & 1 \\
Spouse Native & $4,899,393$ & 0.291 & 0.454 & 0 & 1 \\
Naturalized Citizen & $7,754,857$ & 0.577 & 0.494 & 0 & 1 \\
Petitioned for Citizenship & $7,754,857$ & 0.125 & 0.330 & 0 & 1 \\
American Name Index (Self) & $7,752,221$ & 38.088 & 19.782 & 0.000 & 99.170 \\
American Name Index (Spouse) & $4,905,723$ & 42.502 & 14.083 & 0.000 & 99.019 \\
American Name Index (Children) & $4,445,771$ & 39.747 & 17.154 & 0.000 & 98.060 \\
Birth Year & $7,754,857$ & $1,886.024$ & 15.862 & 1,718 & 1,930 \\
Distance to 21 (Instrument) & $7,754,857$ & 14.876 & 11.393 & 0 & 178 \\
Any Parent from Ireland & $7,754,857$ & 0.062 & 0.242 & 0 & 1 \\
Any Parent from Italy & $7,754,857$ & 0.136 & 0.343 & 0 & 1 \\
Any Parent from Eastern Europe & $7,754,857$ & 0.182 & 0.386 & 0 & 1 \\
Any Parent from Germany & $7,754,857$ & 0.113 & 0.316 & 0 & 1 \\
\hline
\end{tabular}


Figure A1-1: Geographic Distribution of Immigrant Mobilization

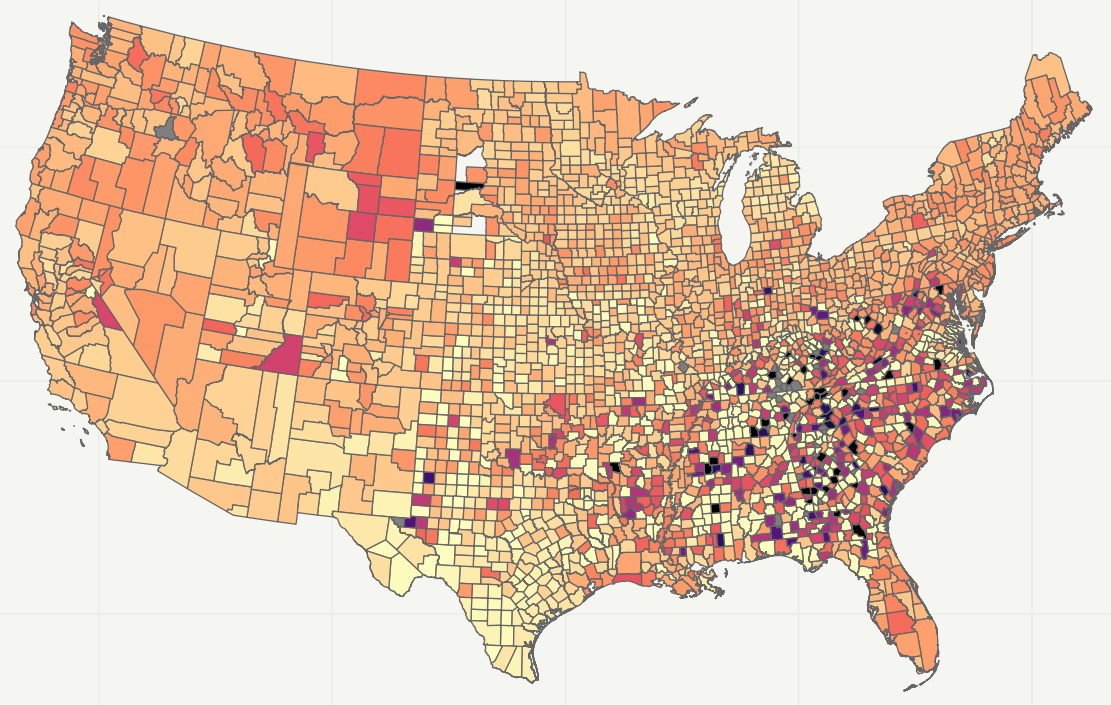

Pct. Veterans (of Immigrants)

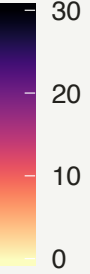


Figure A1-2: Average Differences in Raw Data: Native-Born Spouse

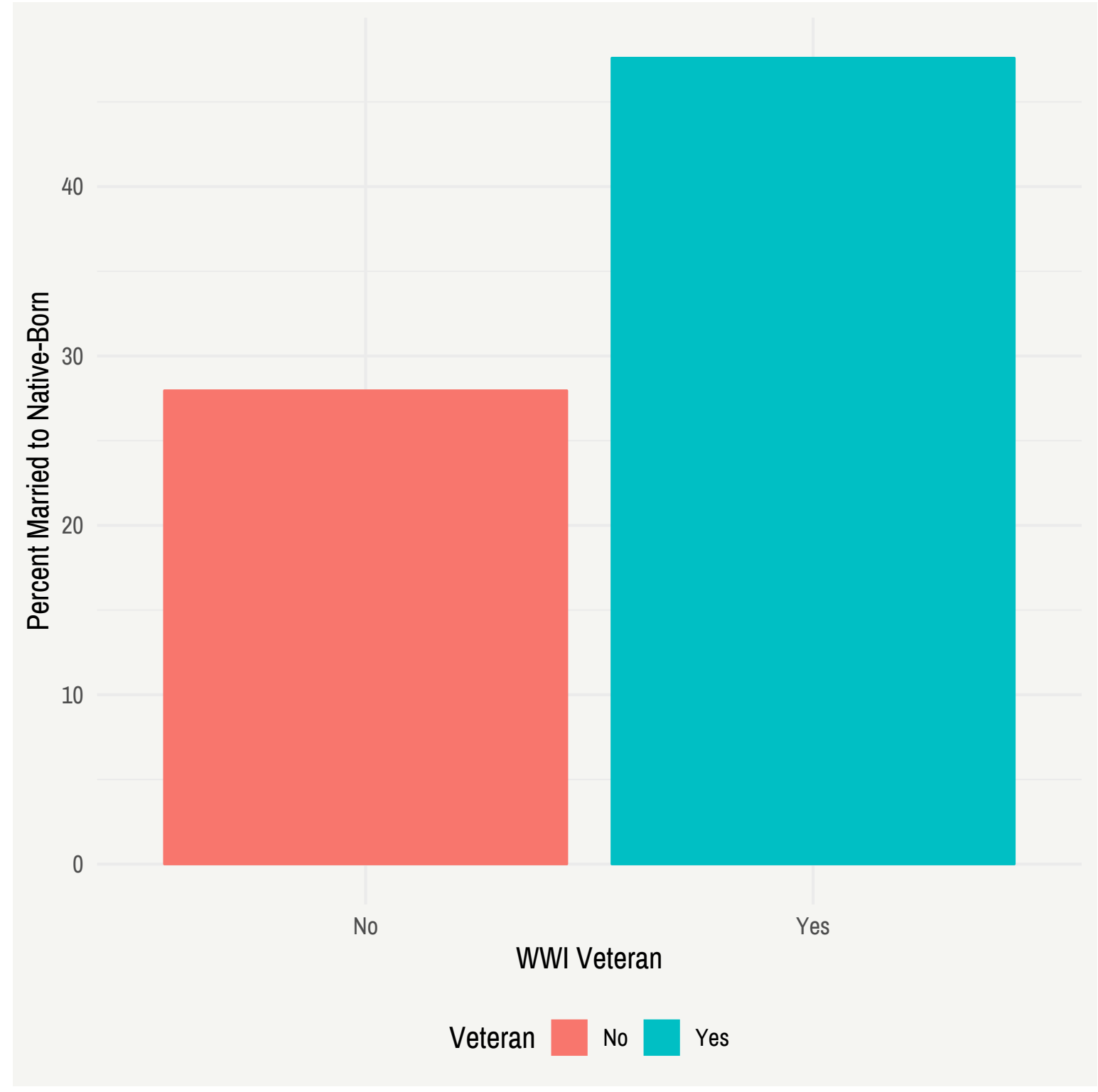

APPENDIX: ROBUSTNESS CHECKS AND ADDITIONAL RESULTS

Raw Differences 
Figure A1-3: Average Differences in Raw Data: Naturalization

80

60

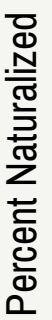

20

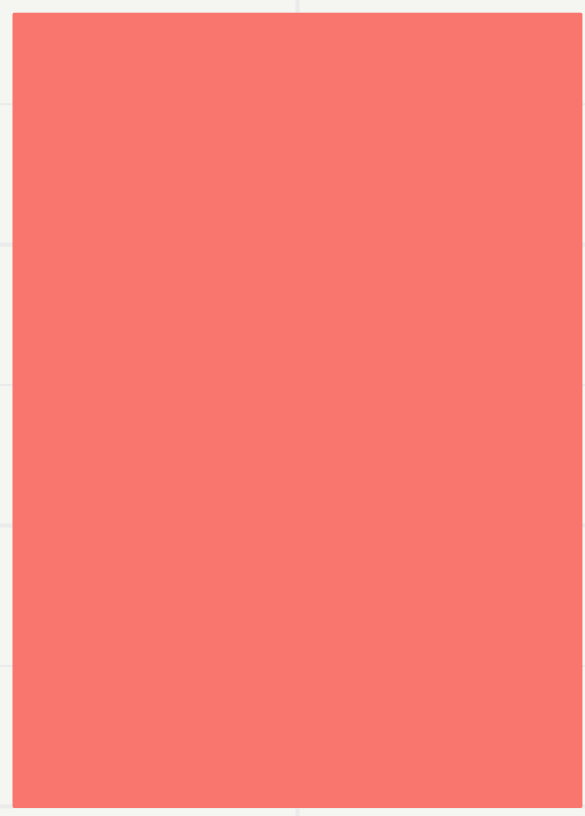

No

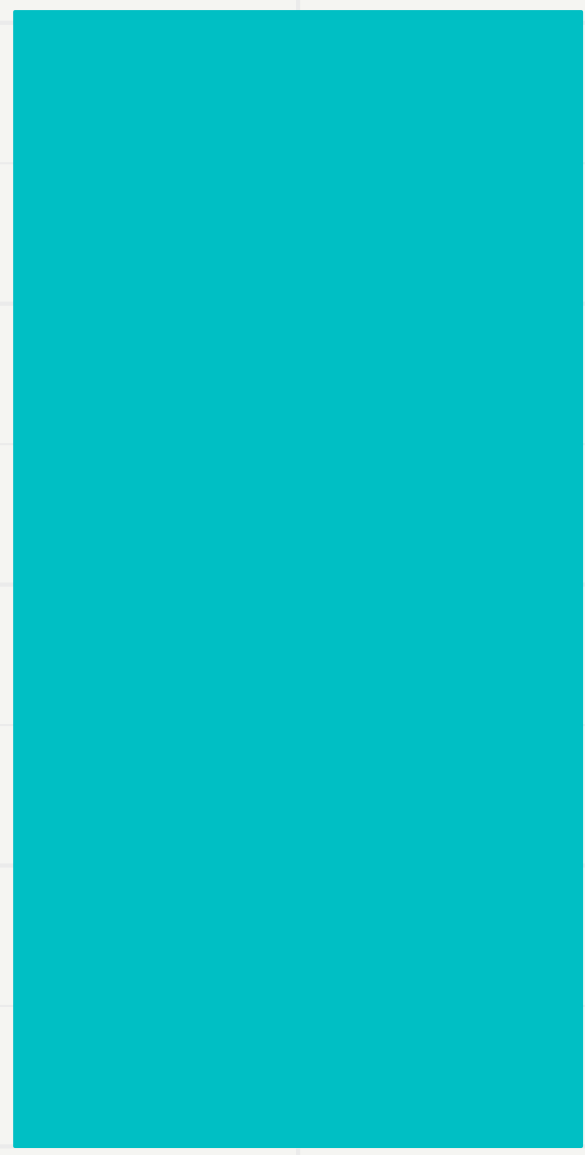

Yes

WWI Veteran

Veteran No Yes 
Figure A1-4: Estimated Effects using Various Matching Techniques

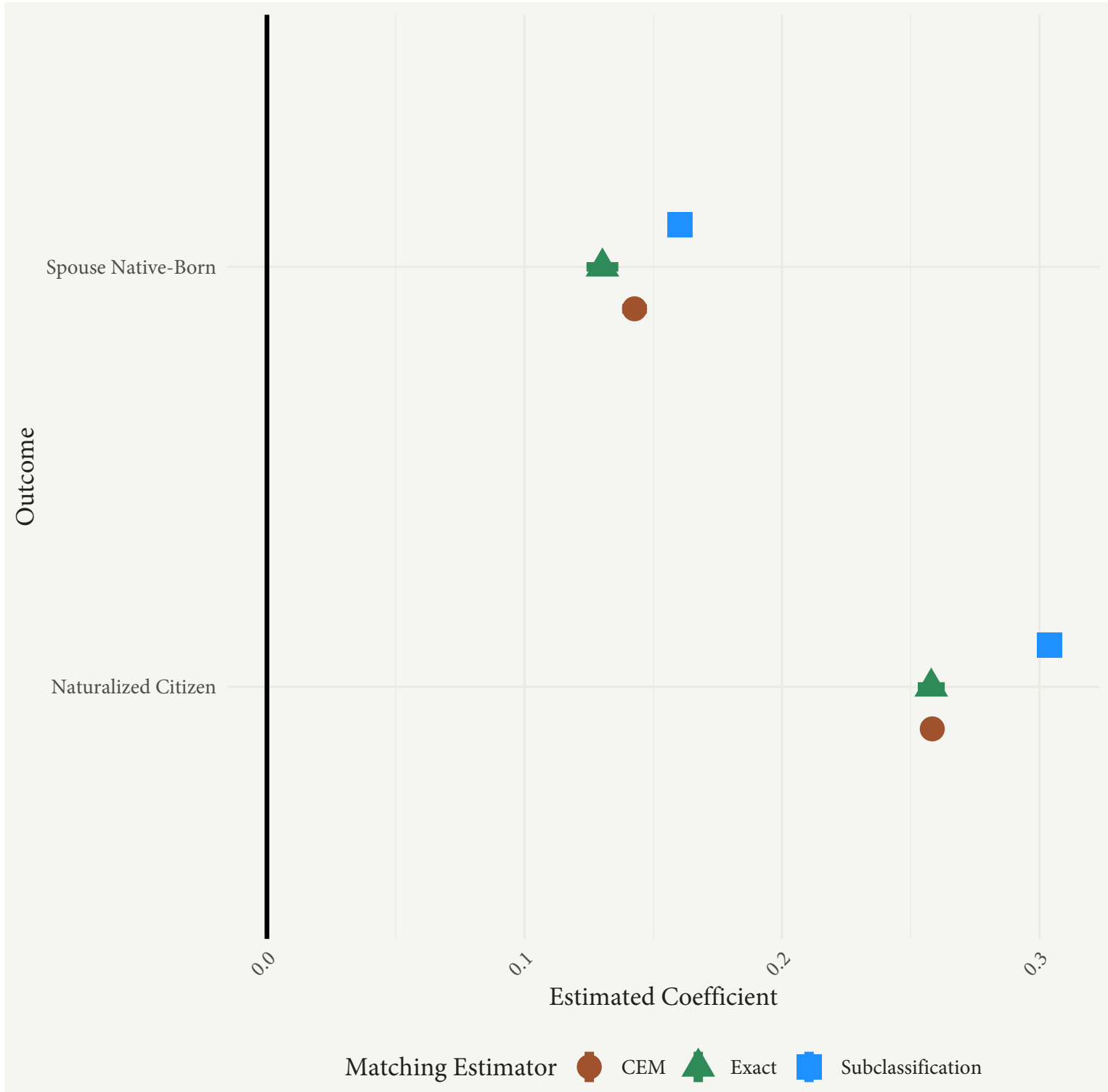

Matching Estimates 
OLS Just County Fixed Effects

Table A1-2: Effect of WWI Veteran Status on Cultural Assimilation: OLS

\begin{tabular}{lcc}
\hline & Spouse Native-Born & Naturalized \\
& $(1)$ & $(2)$ \\
\hline WWI Veteran & $0.155^{* * *}$ & $0.294^{* * *}$ \\
& $(0.001)$ & $(0.001)$ \\
Birth Year & $\checkmark$ & $\checkmark$ \\
Ethnicity Fixed Effects & $\checkmark$ & $\checkmark$ \\
County Fixed Effects & $\checkmark$ & $\checkmark$ \\
Ctrl. Group Mean & 0.28 & 0.564 \\
$\mathrm{~N}$ & $4,899,393$ & $7,754,857$ \\
\hline
\end{tabular}

${ }^{*} \mathrm{p}<.1 ;{ }^{* *} \mathrm{p}<.05{ }^{* * *} \mathrm{p}<.01$

Heteroskedastic robust standard errors in parentheses. 
OLS Just County and Year of Immigration Fixed Effects

Table A1-3: Effect of WWI Veteran Status on Cultural Assimilation: OLS

\begin{tabular}{lcc}
\hline & Spouse Native-Born & Naturalized \\
& $(1)$ & $(2)$ \\
\hline WWI Veteran & $0.228^{* * *}$ & $0.267^{* * *}$ \\
& $(0.001)$ & $(0.001)$ \\
Birth Year Linear & $\checkmark$ & $\checkmark$ \\
Year of Immigration Fixed Effects & $\checkmark$ & $\checkmark$ \\
Ethnicity Fixed Effects & $\checkmark$ & $\checkmark$ \\
County Fixed Effects & $\checkmark$ & $\checkmark$ \\
Ctrl. Group Mean & 0.28 & \\
$\mathrm{~N}$ & $4,899,393$ & $7,754,857$ \\
\hline${ }^{*} \mathrm{p}<.1 ; * * \mathrm{p}<.05 ;{ }^{* * *} \mathrm{p}<.01$ & & \\
Heteroskedastic robust standard errors in parentheses. &
\end{tabular}


OLS Just County and Birth Cohort Fixed Effects

Table A1-4: Effect of WWI Veteran Status on Cultural Assimilation: OLS

\begin{tabular}{lcc}
\hline & Spouse Native-Born & Naturalized \\
& $(1)$ & $(2)$ \\
\hline WWI Veteran & $0.170^{* * *}$ & $0.295^{* * *}$ \\
& $(0.001)$ & $(0.001)$ \\
Birth Year Fixed Effects & $\checkmark$ & $\checkmark$ \\
Ethnicity Fixed Effects & $\checkmark$ & $\checkmark$ \\
County Fixed Effects & $\checkmark$ & $\checkmark$ \\
Ctrl. Group Mean & 0.28 & 0.564 \\
$\mathrm{~N}$ & $4,899,393$ & $7,754,857$ \\
\hline${ }^{*} \mathrm{p}<.1 ;{ }^{* *} \mathrm{p}<.05 ;{ }^{* * *} \mathrm{p}<.01$ & & \\
Heteroskedastic robust standard errors in parentheses.
\end{tabular}


Robustness of OLS Results to Clustering Standard Errors

Table A1-5: Effect of WWI Veteran Status on Cultural Assimilation: OLS

\begin{tabular}{lcc}
\hline & Spouse Native & Naturalized \\
& $(1)$ & $(2)$ \\
\hline WWI Veteran & $0.147^{* * *}$ & $0.251^{* * *}$ \\
& $(0.003)$ & $(0.010)$ \\
Birth Year Fixed Effects & $\checkmark$ & $\checkmark$ \\
Year of Immigration Fixed Effects & $\checkmark$ & $\checkmark$ \\
Ethnicity Fixed Effects & $\checkmark$ & $\checkmark$ \\
County Fixed Effects & $\checkmark$ & $\checkmark$ \\
N & $4,899,393$ & $7,754,857$ \\
\hline${ }^{*} \mathrm{p}<.1 ;{ }^{* *} \mathrm{p}<.05 ;{ }^{* * *} \mathrm{p}<.01$ & & \\
Standard errors clustered by birth year in parentheses.
\end{tabular}


Robustness of OLS Results to Trimming Sample to only Individuals from Birth Cohorts with Positive Probability of begin a Veteran

Table A1-6: Effect of WWI Veteran Status on Cultural Assimilation: OLS

\begin{tabular}{lcc}
\hline & Spouse Native-Born & Naturalized \\
& $(1)$ & $(2)$ \\
\hline WWI Veteran & $0.139^{* * *}$ & $0.257^{* * *}$ \\
& $(0.001)$ & $(0.001)$ \\
Birth Year Fixed Effects & $\checkmark$ & $\checkmark$ \\
Year of Immigration Fixed Effects & $\checkmark$ & $\checkmark$ \\
Ethnicity Fixed Effects & $\checkmark$ & $\checkmark$ \\
County Fixed Effects & $\checkmark$ & $\checkmark$ \\
$\mathrm{N}$ & $3,029,490$ & $4,740,448$ \\
\hline
\end{tabular}

${ }^{*} \mathrm{p}<.1 ;{ }^{* *} \mathrm{p}<.05 ;{ }^{* * *} \mathrm{p}<.01$

Heteroskedastic robust standard errors in parentheses. 


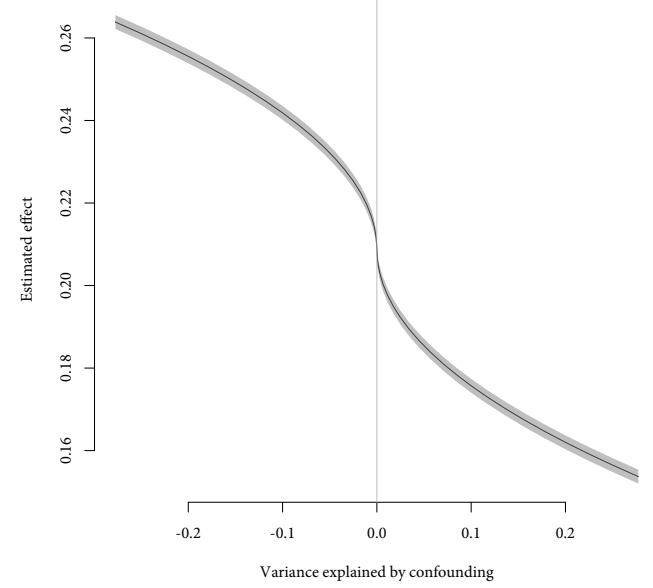

(a) Spouse Native-Born

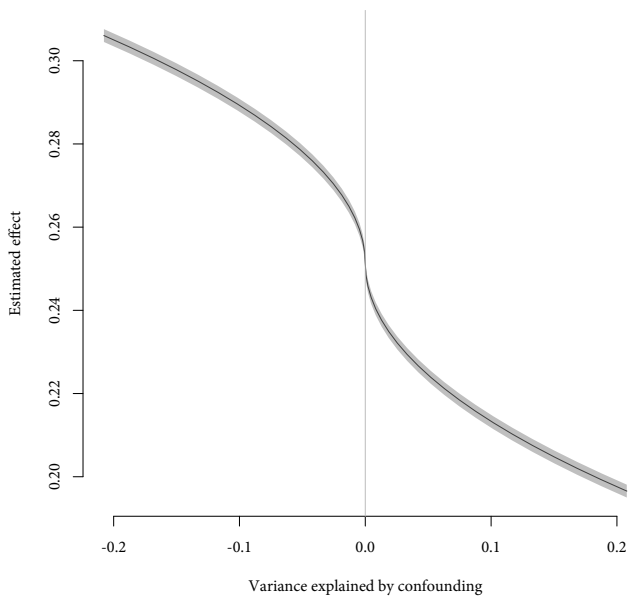

(b) Naturalization

Figure A1-5: Sensitivity Analysis of Ignorability Assumption

\section{Sensitivity Analysis to Selection-on-Observables}

Effect Moderation by Baseline Ethnic Group Integration 


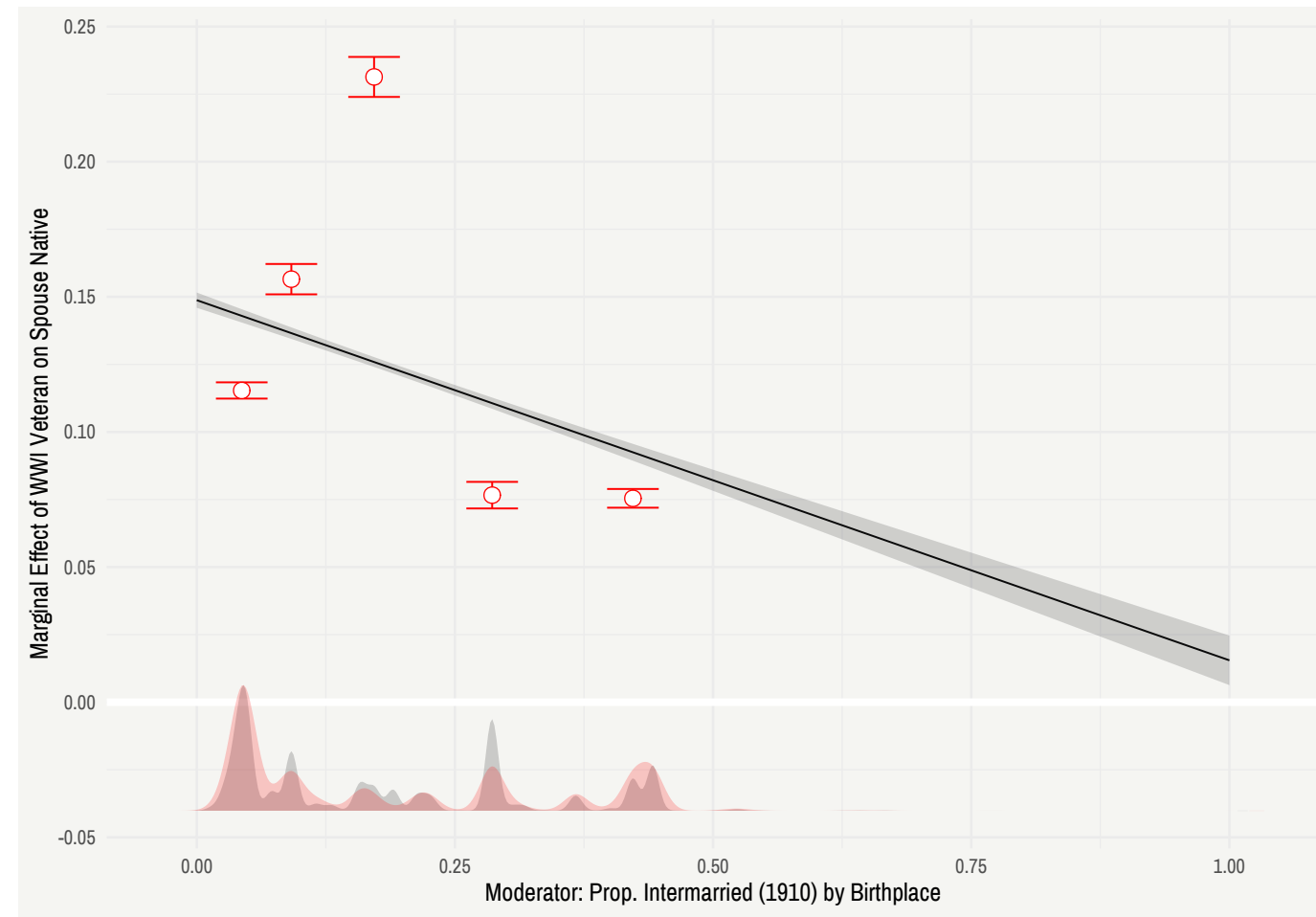

(a) Spouse Native-Born

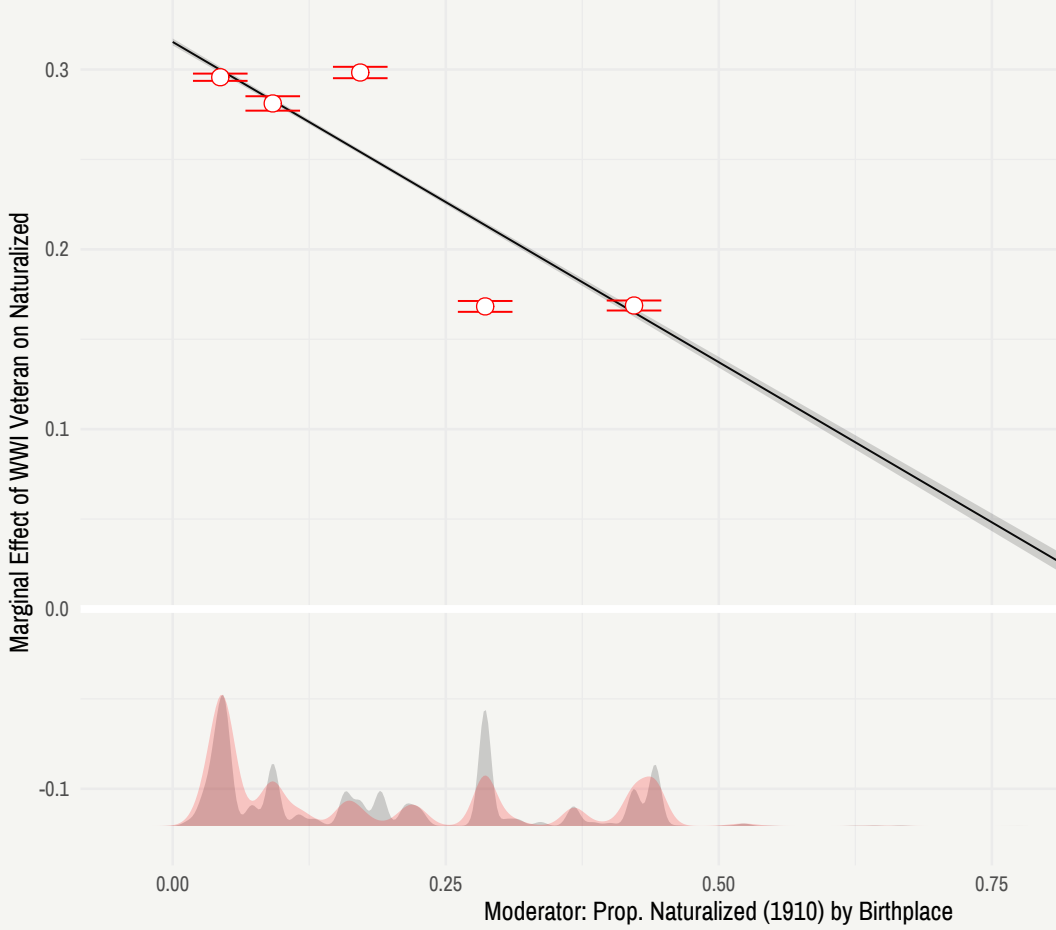

(b) Naturalization

Figure A1-6: Effect Moderation by Baseline Ethnic Group Integration in 1910 
Which types of immigrants seemed to benefit most from military service? I investigate this question by looking at effect moderation by the immigrant's ethnic group's baseline integration rates in 1910 respective to a given outcome. This allows me to explore whether it was the immigrants who were already most integrated to begin with who benefited the most from military service or those who were not to begin with. Figure A1-6 plots the linear regression fit as well as the effect among the quantiles of the baseline (the point and error bars) (Hainmueller, Mummolo, and Xu 2019). For social integration as proxied by intermarriage, it seems that those individuals from groups who were moderately integrated prior to the war seemed to have the largest impact. For political integration as proxied by naturalization, it seems that individuals who were the least integrated to begin with seemed to have the largest response to military service. Thus, this evidence is consistent with the idea that the mechanisms behind military-led integration should matter the most for those who were less integrated to begin with. 
Figure A1-7: Raw Binned First-Stage Relationship between Distance to Cohort Service Peak and Probability of being a Veteran

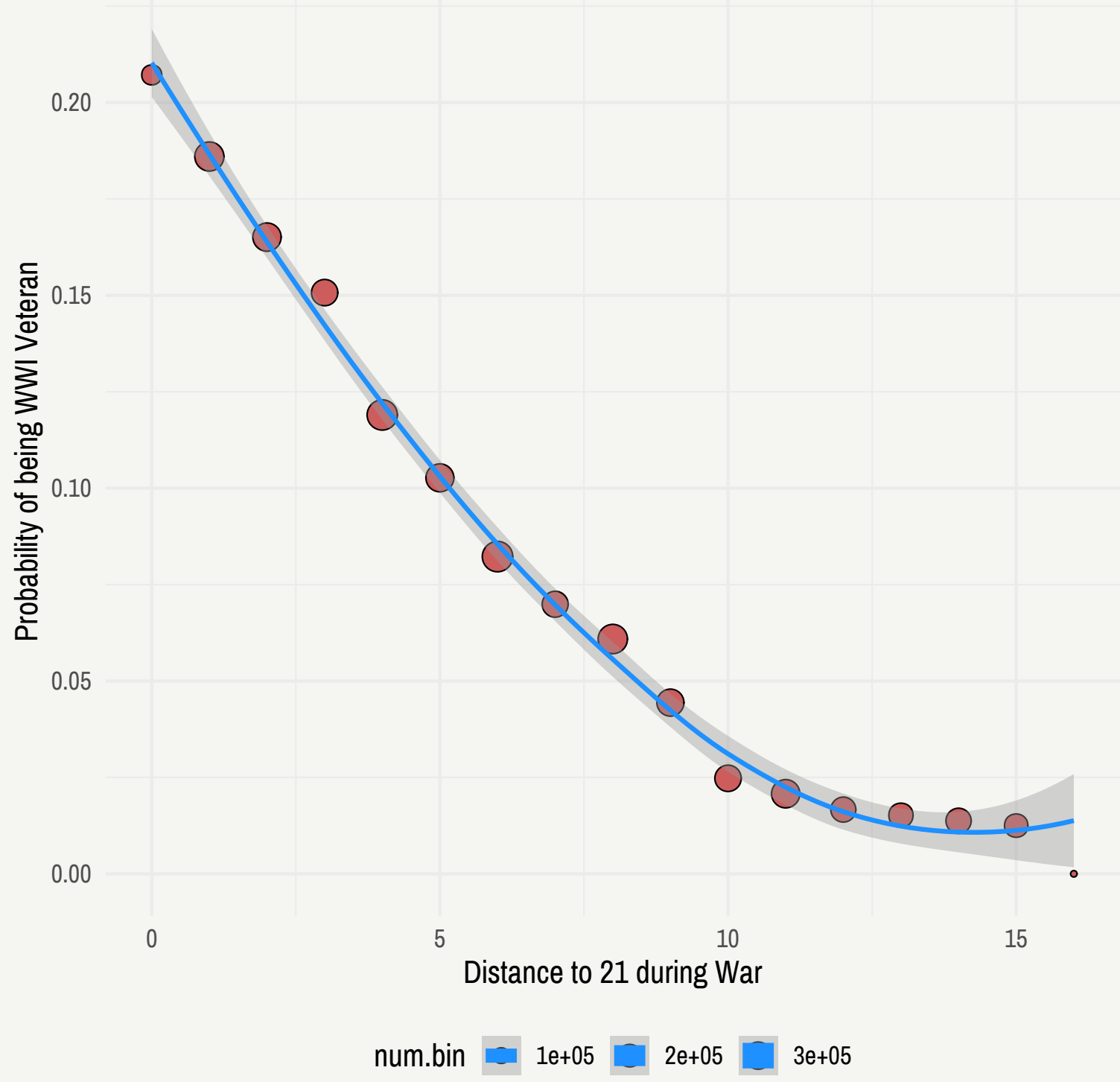

Raw First-Stage Relationship 
Figure A1-8: Raw Binned First-Stage Relationship between Distance to Cohort Service Peak and Probability of being a Veteran by Ethnic Group

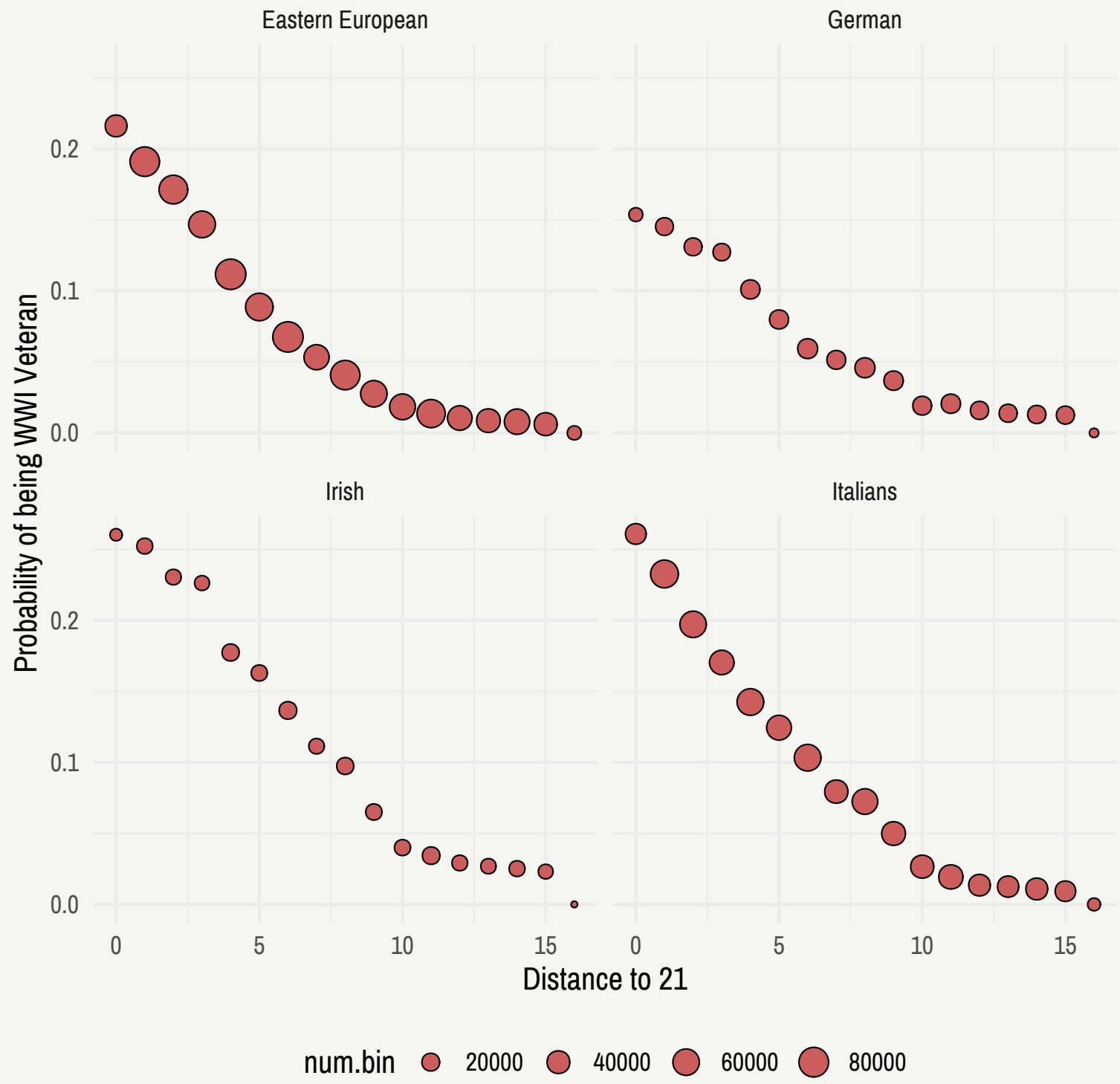


Robustness of First-Stage Results to Differential Birth Cohort Trends

Table A1-7: First-Stage Relationship between Distance to 21 and WWI Veteran Status: Robustness to Birth Cohort Trends

\begin{tabular}{|c|c|c|}
\hline & \multicolumn{2}{|c|}{ WWI Veteran } \\
\hline & (1) & (2) \\
\hline Distance to 21 during War & $\begin{array}{c}-0.027^{* * *} \\
(0.002)\end{array}$ & $\begin{array}{c}-0.027^{* * *} \\
(0.002)\end{array}$ \\
\hline Birth Year Quadratic & $\checkmark$ & $\checkmark$ \\
\hline Ethnicity Fixed Effects & $\checkmark$ & $\checkmark$ \\
\hline State Fixed Effects & $\checkmark$ & \\
\hline County Fixed Effects & & $\checkmark$ \\
\hline State by Birth Year Trends & $\checkmark$ & \\
\hline County by Birth Year Trends & & $\checkmark$ \\
\hline Year of Immigration Fixed Effects & $\checkmark$ & $\checkmark$ \\
\hline $\mathrm{N}$ & 237,040 & 237,040 \\
\hline Adjusted $\mathrm{R}^{2}$ & 0.069 & 0.070 \\
\hline
\end{tabular}




\section{Reduced Form Results}

Table A1-8: Reduced Form Effect of Distance to Midpoint of WWI on Cultural Assimilation: Ordinary Least Squares

\begin{tabular}{lcc}
\hline & Spouse Native & Naturalized \\
& $(1)$ & $(2)$ \\
\hline WWI Veteran & $-0.003^{* *}$ & $-0.009^{* * *}$ \\
& $(0.001)$ & $(0.001)$ \\
Birth Year Quadratic & $\checkmark$ & $\checkmark$ \\
Year of Immigration Fixed Effects & $\checkmark$ & $\checkmark$ \\
Ethnicity Fixed Effects & $\checkmark$ & $\checkmark$ \\
County Fixed Effects & $\checkmark$ & $\checkmark$ \\
$\mathrm{N}$ & $3,029,552$ & $4,740,806$ \\
\hline$* \mathrm{p}<1 ;{ }^{* *} \mathrm{p}<.05 ; * * * \mathrm{p}<01$ & &
\end{tabular}

${ }^{*} \mathrm{p}<.1 ;{ }^{* *} \mathrm{p}<.05 ;{ }^{* * *} \mathrm{p}<.01$

Standard errors clustered by birth year in parentheses. 
Robustness of IV Results to Trimming Sample

Table A1-9: Effect of WWI Veteran Status on Cultural Assimilation: Two-Stage Least Squares (Robustness to Trimming Younger Cohorts)

\begin{tabular}{lcc}
\hline & Spouse Native & Naturalized \\
& $(1)$ & $(2)$ \\
\hline WWI Veteran & $0.095^{* *}$ & $0.313^{* * *}$ \\
& $(0.037)$ & $(0.052)$ \\
Birth Year Quadratic & $\checkmark$ & $\checkmark$ \\
Year of Immigration Fixed Effects & $\checkmark$ & $\checkmark$ \\
Ethnicity Fixed Effects & $\checkmark$ & $\checkmark$ \\
County Fixed Effects & $\checkmark$ & $\checkmark$ \\
N & $2,958,459$ & $4,233,014$ \\
\hline
\end{tabular}

${ }^{*} \mathrm{p}<.1 ;{ }^{* *} \mathrm{p}<.05 ;{ }^{* * *} \mathrm{p}<.01$

Standard errors clustered by birth year in parentheses.

Robustness of ANI Results to IV Bias Correction Strategy

Table A1-10: Effect of WWI Veteran Status on Naming Patterns: Two-Stage Least Squares (BiasCorrected Estimates)

\begin{tabular}{|c|c|c|c|c|}
\hline & $\begin{array}{l}\text { Spouse ANI } \\
\text { (1) }\end{array}$ & $\begin{array}{l}\text { Children's Avg. ANI } \\
\text { (2) }\end{array}$ & $\begin{array}{l}\text { Spouse ANI (Bias-Corrected) } \\
\text { (3) }\end{array}$ & $\begin{array}{l}\text { Children's Avg. ANI (Bias-Corrected) } \\
\text { (4) }\end{array}$ \\
\hline Distance to 21 & $\begin{array}{c}0.012 \\
(0.019)\end{array}$ & $\begin{array}{l}0.064^{*} \\
(0.034)\end{array}$ & & \\
\hline WWI Veteran & & & $\begin{array}{r}3.497^{* * *} \\
(0.497)\end{array}$ & $\begin{array}{c}5.865^{* * *} \\
(1.488)\end{array}$ \\
\hline Birth Year Quadratic & $\checkmark$ & $\checkmark$ & $\checkmark$ & $\checkmark$ \\
\hline Year of Immigration Fixed Effects & $\checkmark$ & $\checkmark$ & $\checkmark$ & $\checkmark$ \\
\hline Ethnicity Fixed Effects & $\checkmark$ & $\checkmark$ & $\checkmark$ & $\checkmark$ \\
\hline County Fixed Effects & $\checkmark$ & $\checkmark$ & $\checkmark$ & $\checkmark$ \\
\hline $\mathrm{N}$ & 570,879 & 872,739 & $2,745,848$ & $3,403,569$ \\
\hline
\end{tabular}

